\title{
Evaluation of Early Stage Cleft Lip and Palate Using 3D-Ultral Sonography Screening
}

\author{
Yerbolat Kakei, Jargal Janchiv, Munkhbatar Dagvasumberel, Munkhjargl Ochirpurev, \\ Dorjikhuu Amaglanbattar, Abirmid Amgalanbatar
}

Govi-Altai Medical School, Mongolian National University of Medical Sciences, MNUMS, Ulaanbaatar, Mongolia

Email:erbolat@mnums.edu.mn

How to cite this paper: Kakei, Y., Janchiv, J., Dagvasumberel, M., Ochirpurev, M., Amaglanbattar, D. and Amgalanbatar, A. (2019) Evaluation of Early Stage Cleft Lip and Palate Using 3D-Ultral Sonography Screening. Open Journal of Applied Sciences, 9, 409-437. https://doi.org/10.4236/ojapps.2019.95035

Received: January 15, 2019

Accepted: May 28, 2019

Published: May 31, 2019

Copyright $\odot 2019$ by author(s) and Scientific Research Publishing Inc. This work is licensed under the Creative Commons Attribution International License (CC BY 4.0).

http://creativecommons.org/licenses/by/4.0/

\begin{abstract}
Congenital cleft lip palate occurs heterogeneously worldwide. Out of the one-hundred and thirty million newborns worldwide, 3.6 million identified with a disability, 7.6 million (approximately $5.8 \%$ ) being born with a congenital anomaly. Additionally, $7.5 \%$ of them are registered with having cleft lip palate. In Mongolia, the statistics from the Mongolia Health Department reported that in 2012 cleft lip palate occurred among 1 out of 1072 individuals in Mongolia [1]. Over the years, there have been many measures taken to ameliorate these issues around the world. Recently, the sophisticated three-dimensional ultra-sonography equipment is evaluable in pediatric science. Thanks to this equipment, we are able to detect the orofacial defects and diagnose infants properly in advance. The purpose of this study is to evaluate the lip and palate of a fetus by using three-dimensional ultra-sonography in the second and third trimester of gestational period. Our research aims to detect fetus defects in the early stage of birth and diagnose it in advance [9]. Due to the lack of research on the above-mentioned issues in Mongolia, we decided to conduct this research by using three-dimensional ultra-sonography to detect and diagnose congenital cleft lip palate. By doing this research, we will be able to better assist those suffering from congenital malformation in Mongolia.
\end{abstract}

\section{Keywords}

Cleft Lip and Palate, 3D-Ultral Sonography Screening

\section{Introduction}

Out of the one-hundred and thirty million newborns worldwide, 7.6 million (approximately 5.8\%) are born with a congenital anomaly. Of those new born, 
3.6 million are identified with disabilities and 3.2\% die due to congenital anomalies. Additionally, $7.5 \%$ of them are registered with having cleft lip palate. Congenital cleft lip palate occurs heterogeneously worldwide. Most congenital cleft lip palate occurs highly among the following countries: China, Japan, South Korea and Indonesia. The occurrence rate of congenital cleft lip palate in these countries is 1 in 500 - 600 live births per country. These occurrences are classified as a high level of cleft lip palate incidence. Recently, the statistics from the Mongolia Health Department reported that in 2012 cleft lip palate occurred among 1 out of 1072 individuals in Mongolia [1]. Over the last three years, roughly 370 newborns were registered with malformation. Out of those newborn, $23.8 \%$ account for congenital cleft lip palate; $80 \%$ of them suffer from congenital cleft lip palate and $20 \%$ of them suffer from another form of abnormal defects. Experts have proven that during gestational period, $60 \%$ of prenatal defects usually occur during the antenatal period [2].

Over the years, there have been many measures taken to ameliorate these issues around the world. For instance, modern prenatal medicine's purpose is to help deliver a healthy child and prevent newborns from being born without any defects. One of the most important matters is detecting fetal defects in the early stages of pregnancy and diagnosing the abnormal problems during gestational period. Recently, the sophisticated three-dimensional ultra-sonography equipment is evaluable in pediatric science. Thanks to this equipment, we are able to detect the orofacial defects and diagnose infants properly in advance. The three-dimensional ultra-sonography equipment is more suitable for infants as it doesn't cause any pain in comparison to the other ultra sound equipment [3]. Furthermore, the following are some of the benefits of the three-dimensional ultra-sonography equipment: doesn't cause any harm, doesn't produce large rays, and doesn't demand any pre-preparations to detect defects. The three-dimensional ultra-sonography equipment is an economical and useful tool to utilize. This equipment takes a short amount of time to produce fast results. The three-dimensional ultra-sonography can provide more precise image of the defects and malformation of infants. The three-dimensional ultra-sonography is used to provided detection of normalities of gestation, early diagnose, complication with mother and fetus, prevention and treatment [3]. This equipment has a clear contrast without an imagined coincidence and is able to diagnose malformations properly. One of the most urgent issues is to be able to use this three-dimensional ultra-sonography in practice to detect and diagnose the fetus anomaly or malformation in the early stages of pregnancy [4] [5] [6]. Thus, those who pay good attention of diagnosing anomaly when using this equipment are more likely to prevent malformation of infants.

In Mongolia, out of 1000 live births, $20.2 \%$ of births were reported to having prenatal mortality, $62.7 \%$ of infant mortality, and $63.5 \%-83.5 \%$ of births were premature mortality [7]. One of the main causes of prenatal mortality is due to slow fetal growth, placenta insufficiency, and miscarriage. Therefore, our research aims to assess and detect fetus defects in the early stage of birth and diagnose it in ad- 
vance [8]. Due to the lack of research on the above-mentioned issues in Mongolia, we decided to conduct this research by using three-dimensional ultra-sonography to detect and diagnose congenital cleft lip palate. By doing this research, we will be able to better assist those suffering from congenital malformation in Mongolia.

\section{Aim of Study}

The purpose of this study is to evaluate the lip and palate of a fetus by using three-dimensional ultra-sonography in the second and third trimester of gestational period.

\section{Objective of Study}

- Understand the micro and macro structure indicators of the cleft of the fetus during the second and third trimester of the gestational period and compare it with sample cleft indicators by using the three-dimensional ultra-sonography.

- To study the micro and macro structure indicators of the palate of the fetus during the second and third trimester of gestational period and compare it with sample palate indicators by using the three-dimensional ultra-sonography.

- To study the specific structure and development of cleft and palate.

\section{Practical Significance of Study}

The significance of this researcher is to detect congenital cleft lip and palate in the early stage, evaluate the development of lips and palate and determine morphometry indicator of lip and palate of the fetus. Based on previous studies, we understand that the muscular epithelium fiber of the upper lip grows toward the lateral process within 20 weeks and creates muscular complex. If an infant is diagnosed with malformed clefts before 20 weeks during gestational period, a fetal surgical operation must be performed in order for the infant to recover without any scars.

\section{Ethics of Study}

Approval to conduct this research was obtained on November 28th, 2015 during meeting (No 13-02\1A) held by the medical ethical board of Biomedical University of Mongolian National University of Medical Science (MNUMS). The methodology of the research was addressed during meeting (No13D/2015.13) with the Biomedical University of MNUMS which was held on November 26th, 2013.

\section{Methodology}

This research was conducted using an epidemiological analytical case-sectional method from the Biomedical University of Mongolian National University of Medical Science (MNUMS).The study includes a total of 34 fetal cadavers between 15.3 - 40 weeks of age. We received the fetal cadaver from the Maternity and Infant hospital in Ulaanbaatar, Mongolia on November $28^{\text {th }}, 2013$ post our approval from the ethic committee. The cadaver samples were stored at the Biomedical University MNUMS. The cause of death of these cadavers was due to non-malformation causes, there were no anomalies related to the development of lips and palate. In addition, 128 fetuses between weeks 19 - 32 were involved in this study in order to detect the characteristics of lips and palate using a 
Three-dimensional ultra-sonography. The cadavars were examined between the time our research received approval (November $28^{\text {th }}, 2013$ ) until the end time of our research (May 2014) at the Tod Delgetse Gynaecological Hospital in Ulaanbaatar, Mongolia. Only cadavers who were in between a 24-hour period post death were included in this study, if the cadaver had passed the 24-hour period and show a sign of body decae, they were excluded from the study. The research participants were selected using a randomized spot check method. This research was conducted and assessed using the following research methods: fetometric measurement, morphometric measurement, histological method and conclusion method.

\section{Data collection}

Before conducting our research, data was collected on pregnant women from Tod-Delgets Hospital (Clear Screening Hospital). The hospital is a private hospital located in Ulaanbaatar, Mongolia. Based on the data collected, we selected a total of 218 pregnant women based on the following criteria: women in the second trimester (19 - 22 weeks) and third trimester (weeks 29 - 30), women giving birth to one child and pregnant women without any diseases. In order to study the structures of lips and palate of 34 cadavers, a total of 102 medicinal preparations were made by micro-morphometric and histological measurements. The measurement of lips and palate were conducted using Accuvix A 30 ultrasonic devices and a three-dimensional ultra-sonography device at Samsung Medicine Company in Ulaanbaatar, Mongolia. The Accuvix A 30 ultrasonic devices had a frequency range of $6 \mathrm{MHZ}$ and was used to detect defected cleft lips and palate. These liner devices were used to detect malformation of lips and palate. During the study we detected congenital malformations which showed an excess fluid in the fetus and others with a lack of fluid. Statistical data was analyzed using SPSS 20 statistical program.

\section{Insert Method}

Cadavers who did not die of non-malformations of digestive system and other disorders (later morning sickness, disorders of maternal organ) the above-mentioned disorders are allowed to participate in the research for fetus chronic oxygen deficiency and placental disorders. The autopsy of the cadaver was used within 24 hours. There were no element changes in the structure of lips and palate by the analysis of autopsy.

\section{Subtraction Method}

- We are not allowed to conduct research on the below mentioned cadavers such as:

- Cadavers with orofacial defects and defects of digestive system. We didn't use the deteriorated autopsy (after 24 hours)

\section{Gazette Formula}

In order to detect the duration of gestation period, we used the Gazette formula according to Käferstein F, Abdussalam M (1999) [9]. If the fetus length is $25 \mathrm{~cm}$, the square root is valuable. If the fetus length will be $25 \mathrm{~cm}$ or the length is divided into 5 .

Voltage Formula 
In addition, the Voltage formula from the Medical Morphmetry Avtandilov. GG (1990) was included in this study. The formula is indicated below:

$$
\mathrm{T}=(\text { Length of body } \times 5.6) / 28 \text {. }
$$

The length of body is multiplied by 5.6 and divided by 28 [10].

$$
\mathrm{T}=\text { is detected in a month. }
$$

The sample of the study was estimated by the approximate accuracy (R) avtandilob method out of which $50 \%$ had an error, $90 \%$ had a probability. The accreditation criteria were $2.0(\mathrm{t})$. In case of reference, quantities 16 unit of materials were used [11] (Table 1).

\section{Sonography Method}

No special preparation was required for cadavers. In order to take a sample, the patient (pregnant women) laid on the bed. A jell was applied on to the patient using frequency band of $6 \mathrm{MHZ}$. Then the average size of the fetus head circumference, abdominal circumference, femur length, height of the upper lip, length of palate was measured three times. Every size was taken according to the international standards of world health organization (WHO).

\section{Transvers size of Fetal Head Circumference}

Picture 1 shows the transvers head circumference using MTSI method, which maps the plane with the brightest, clearest, even lines were used to measure the circumference of the external edges of the lower parietal bone to the upper edge of the parietal bone.

The biparietal diameter should be measured on an axial plane that traverses the thalamus, cavum septum and pellucidin. The calipers should be placed at the outer edges near the calvarial, near the inner edges of the clavarial wall.

\section{Fetal head circumference}

AS depicted in Picture 2 the fetal head circumference incised size was measured from the outer head circumstance.

\section{Abdominal Circumference}

After identifying the location and position of the fetus, the oval shaped amphalic artery was located at $1 / 3$ space from the anterior of the abdominal wall. As

\begin{tabular}{|c|c|c|c|c|}
\hline \multirow{4}{*}{$\begin{array}{c}\text { Estimated } \\
\text { (R) }\end{array}$} & \multicolumn{4}{|c|}{ Probability Threshold (P) } \\
\hline & \multicolumn{2}{|c|}{0.95} & 0.98 & 0.99 \\
\hline & \multicolumn{4}{|c|}{ Confidence criteria $(\mathrm{t})$} \\
\hline & \multicolumn{2}{|c|}{2.0} & 2.5 & 3.0 \\
\hline Approx. Conditions & 0.5 & 16 & 25 & 36 \\
\hline \multirow{3}{*}{ Medium Accuracy } & 0.4 & 25 & 39 & 56 \\
\hline & 0.3 & 45 & 70 & 100 \\
\hline & 0.2 & 100 & 156 & 225 \\
\hline High Accuracy & 1.0 & 400 & 625 & 900 \\
\hline
\end{tabular}

Table 1. Detection based on avtandilod morphologic method. 


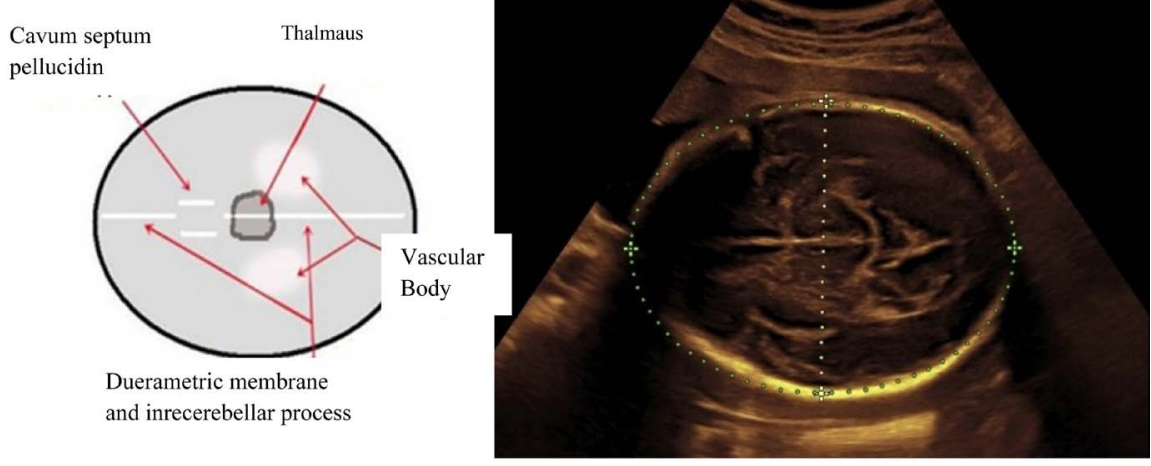

Picture 1. Design used to measure transvers head circumference.

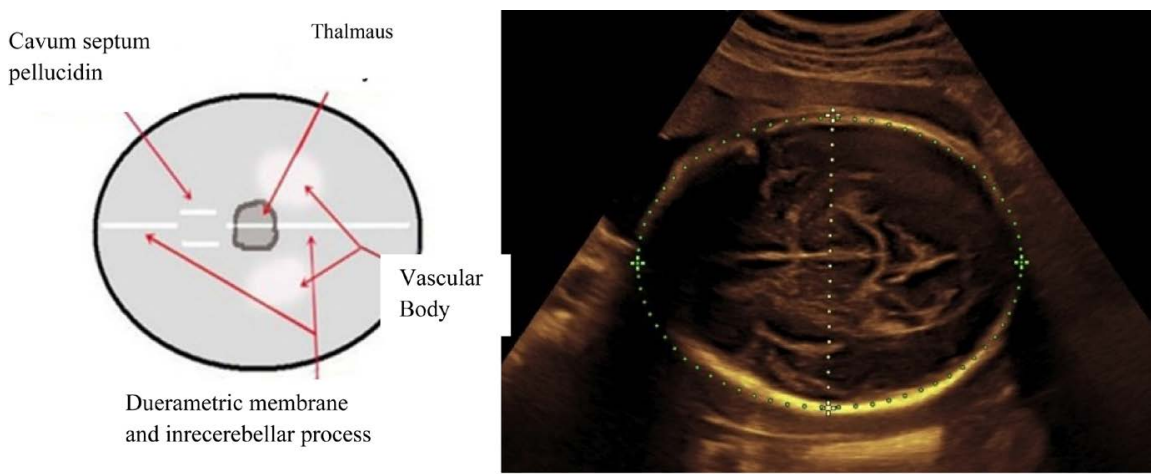

Picture 2. Design used to measure head circumference.

soon as the "Picture 3 " of the stomach was visible, we detected and identified the anterior and posterior oblique transvers size and the abdominal circumference was measured.

\section{Length of femoral bone}

The femoral bone was measured using a straight line depicted in "Picture 4", the upper and lower edges of mappings were identified.

\section{Length of palate}

The length of the fetus palate is measured from the incision of the foramen to the uvula using a straight line. Picture 5 below depicts the measurement of the palate.

\section{Width of palate}

The width of the fetus palate is measured from the right corner of the jaw to the left corner of the jaw. "Picture 6" depicts the measurement procedures.

\section{Height of upper lip}

The height of the upper lip as shown in "Picture 7" was measured along the sagittal plane from the median nasal septum to the edge of the front lip.

\section{Fetometric Measurement}

In order to conduct a Fetometric measurement, we first gathered general information on the fetus. The following information was recorder on the fetus's registration file: fetus height, weight, age, sex, number of samples taken and samples dates. The fetus weight was measured using an electronic weigh of JW-1. 

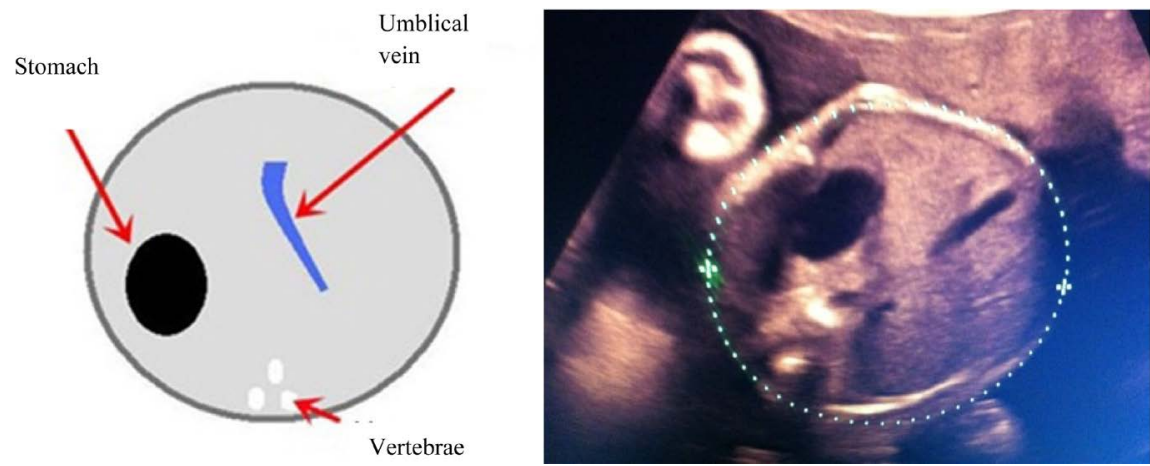

Picture 3. Model used to measure abdominal circumference.
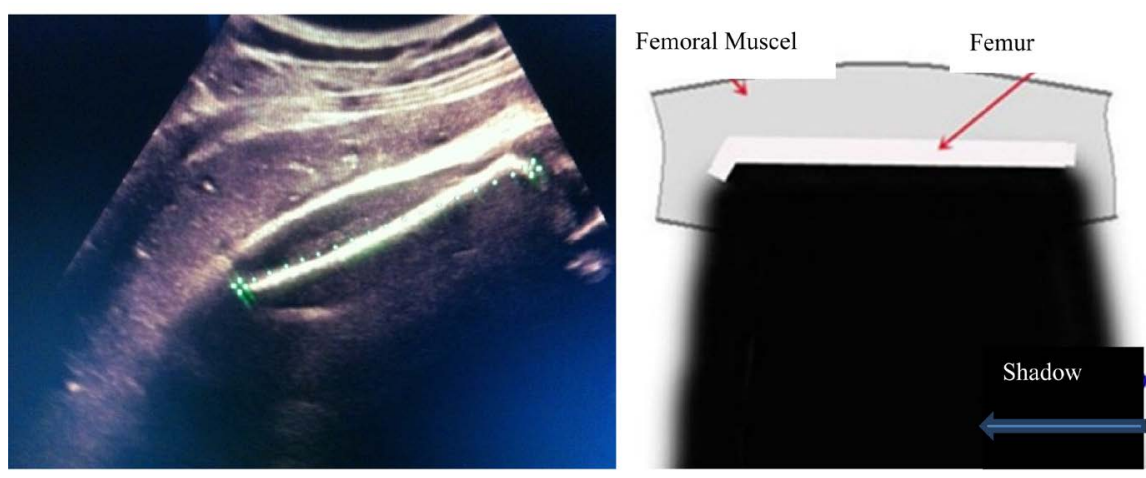

Picture 4. Model to measure length of femoral bone.
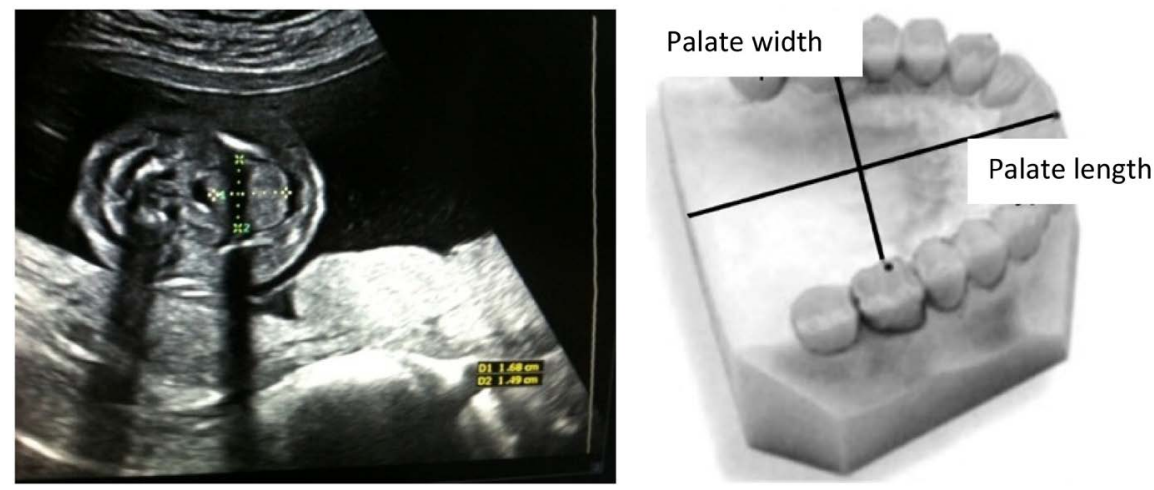

Picture 5. Model used to measure length of palate.
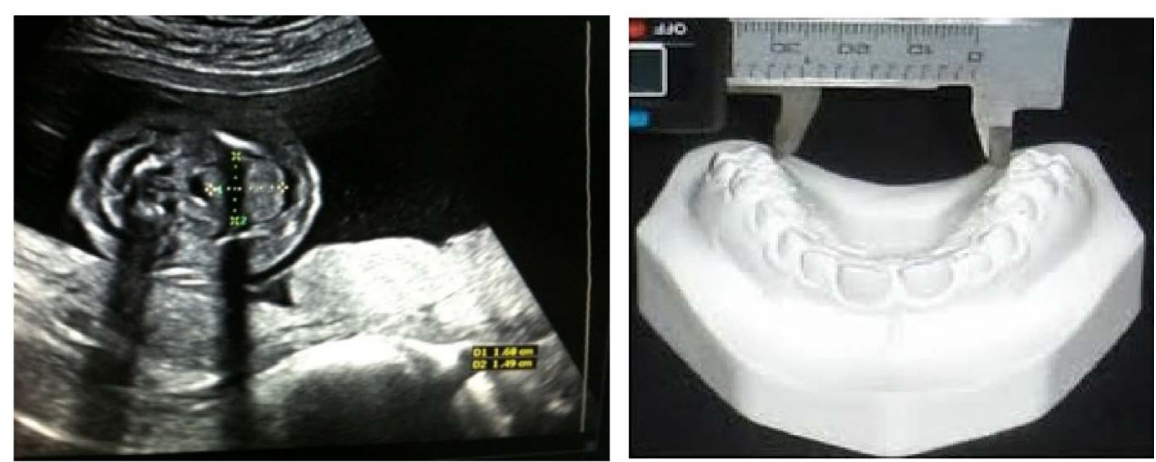

Picture 6. Model used to measure width of palate. 


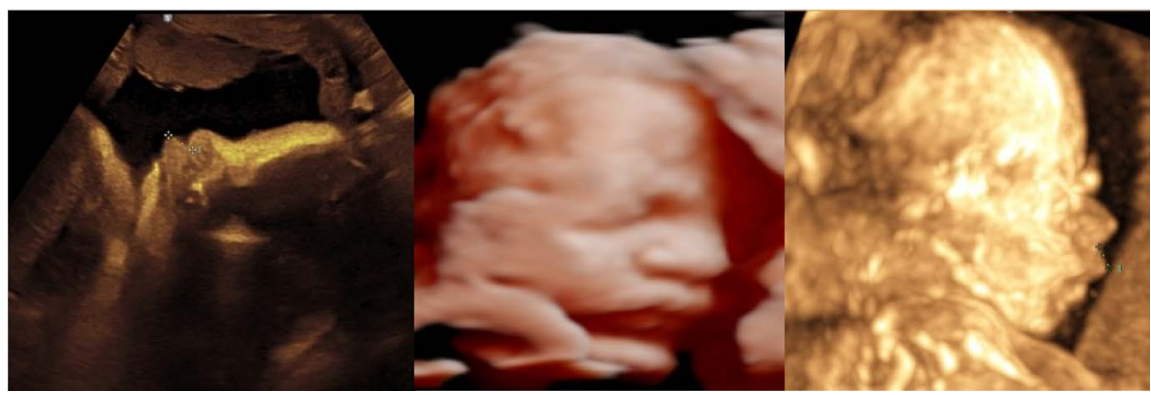

Picture 7. Model used to measure height of upper lip.

The height of the fetus was measured in a vertical position (form head to toe) using a narrow tape divided into millimeter. The purpose of this measurement is to assess the fetus's weight.

\section{Anthropometrics Measurement}

Anthropometrics measurements are measured on cadavers using an iron ruler and compass non-stretchable belt which was precisely divided into millimeters. We used body length, height, head circumference and thoracic circumference in order to determine to measurement of the abdominal circumference of the cadavers. The cadaver's height was measured horizontally between the top of the head to the bottom of the feet. According to the standard of anthropometric measurement, we used calipers, an iron ruled, a non-elastic thin tape to measure the size, length, height, head circumference, chest circumference, and abdominal circumference of the cadaver. The circumference of the head was measured from the protruding forehead to the chest using a non-elastic tape. The tape was wrapped around the axillary bone and to the above the umbilical cord measuring the abdominal circumference [12].

\section{Inference Method}

The fetus was placed into $10 \%-12 \%$ of formula solution for $14-21$ days in order to prepare for strengthening of the cadaver. After this method has been approved by the staff at the anatomy department, we began our experiment once the cadaver was ready to be performed on as shown in "Picture 8". Before measuring the lips and palate, the cadavers were washed properly with flowing water.

\section{Morphometric Measurement}

According to the (L.G. Farkas) method of morphometric measurement, we used a compass and an iron ruler in millimeter scale to measure lips and palate [13]. Our measurement were recorded using the following labels: (B-E) height of upper lip, (A-D $\backslash \mathrm{r})$ height right upper lip (A-D 1 ) height of left upper lip, (B-D) height of philtrum, $(\mathrm{C}-\mathrm{C})$ width of philtrum, (A-Clr) lateral height of the upper lip, (A-Cll) height of left lateral upper lip, (E-C) height of philtrum, (E-G) height of lower lips, (F-F) width of mouth. (B-E) Height of upper lip, (A-D \r) Right height of upper lip, (A-D ll) Right height of upper lip, (B-D) Height of fossa, (C-C) Width of fossa, (A-C\r) Height of right corner of upper lip, (A-Cll) Height of left corner of upper lip, (E-C) height of philtrum, (E-G) Height of space of lower lip and (F-F) Mouths width [27/13] as depicted "Picture 9". 


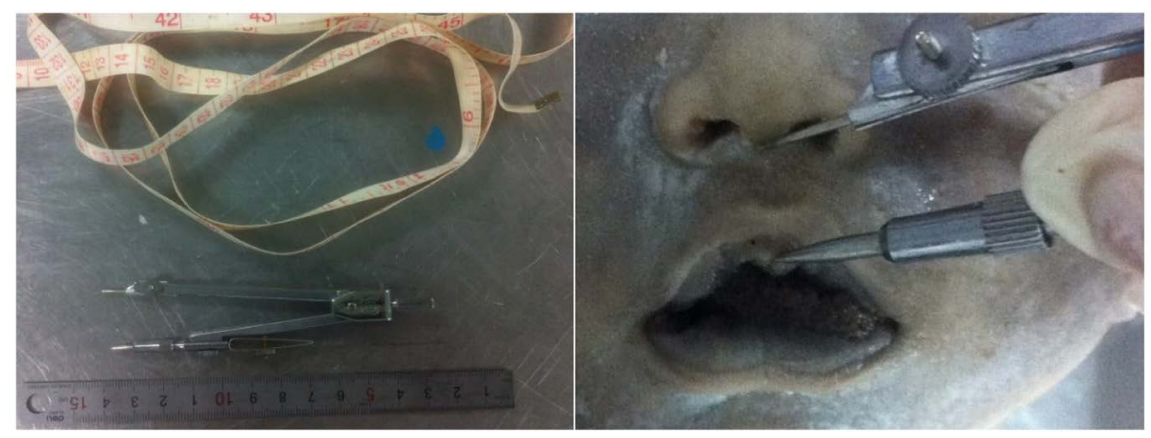

Picture 8. Conditions for measuring lips and palate.
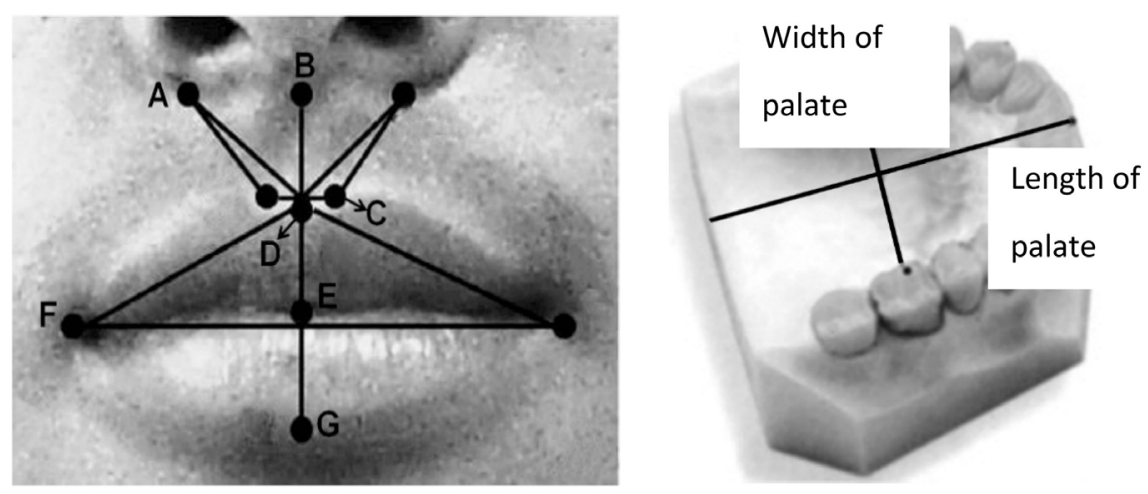

Picture 9. Model used for measuring lips and palate using (Farkas L.G) method [13].

\section{Histological Measurement Method}

To obtain tissue analysis, we wrapped a biopsy sample of lip and palate in a 1 $\times 1$ centimeter cube pieces of gauze and sealed them in $10 \%-15 \%$ formalin reinforcement solution of $5-7$ volume. The samples name and date recorded were included on the lid of the samples and sent to histological laboratory in Ulaanbaatar.

\section{Preparation of Histological Measurement:}

Microbic preparation was taken from the pathology laboratory in Song-Do hospital in Ulaanbaatar using tissue-tek VIP 5JR designed automatic transducer. Tissue-tek VIP 5 JR design automatic block mixer. LEICA DSC1 design microtome was used to employ the histological measurements.

\section{Preparation Steps Taken:}
1) $70 \%$ - Ethanol - 30 Minutes
2) $75 \%$ - Ethanol - 30 Minutes
3) $80 \%$ - Ethanol - 40 Minutes
4) $85 \%$ - Ethanol - 40 Minutes
5) $90 \%$ - Ethanol - 1 Hour
6) $95 \%$ - Ethanol - 1 Hour
7) $95 \%$ - Ethanol - 1 Hour
8) $99.7 \%$ - Ethanol (isopropyl) 1 Hour
9) Xylene 1 Hour
10) Xylene 1 Hour 
11) Parafinn - 1 Hour and 20 Minutes

12) Parafinn - 1 Hour and 20 Minutes

13) Parafinn - 1 Hour and 20 Minutes

14) Parafinn - 1 Hour 20 Minutes Parafinn preparation were carried out under the protocol of micrometric apparatus, which had an incision thickness of 5 $-6 \mathrm{MKM}$

Histological painting method: Harrison's hematoxylin oznpainting method: Techniques: Paintings were carried out on the paraffin incisions

1) Xylene I - 3 minutes

2) Xylene II - 3 minutes

3) Xylene III - 3 minutes

4) Ethanol - $96 \%$ - 3 minutes

5) Ethanol - 96\% - 3 minutes

6) Ethanol - 96\% - 3 minutes

7) Flowing water - 1 minutes

8) Distilled water - 1 minutes

9) hematoxylin - 5 minutes

10) flowing water - 5 minutes

11) Ozn - 30 second

12) Ethanol - 70\% - 30 second

13) Ethanol $80 \%$ - 30 second

14) Ethanol - 90\% - 30 second

15) Ethanol - 96\% - 30 second

16) Xylene - 1 minute

17) Xylene - 1 minute

18) Xylene - 1 minute

19) Cover paintings

Measurement Results: In order to measure the histological tissue according to the methods of Avtandilov. G, Collah Y., using microscope of DISKUS 4.2 Version programming [11]. The nucleus was painted blue and histological plasma was painted pink.

\section{Results}

When measuring the height of the upper lip of fetus in the second trimester, our measurement depicted in Table 2 shows the height of the upper lip was $6.0 \pm 0.6$ $\mathrm{mm}$ in the second trimester. In the third trimester, the height of the upper lip measurement had a result of $9.4 \pm 1.0 \mathrm{~mm}$. On the other hand, when we assessed the measurement of the upper lip based on gender we concluded to the following results; we measured a height of $6.0 \pm 0.6 \mathrm{~mm}$ for male and $5.9 \pm 0.7 \mathrm{~mm}$ for female in the second trimester and $9.4 \pm 1.0 \mathrm{~mm}$ for male and $9.5 \pm 0.9 \mathrm{~mm}$ for female fetus in the third trimester. In addition, there was no statistical significant difference that was observed between the male and female fetus. Therefore, comparing the second and third trimester, we concluded that there is not distinction of height of upper lip based on gender (Table 3). 
Table 2. The height of upper lip ( $\mathrm{mm}$ ) based on age group.

\begin{tabular}{ccc}
\hline Indicators & $\begin{array}{c}\text { II Trimester } \\
\mathbf{M} \pm \mathbf{S D}\end{array}$ & $\begin{array}{c}\text { III Trimester } \\
\mathbf{M} \pm \mathrm{SD}\end{array}$ \\
\hline Weeks & 117 & 101 \\
Average & $6.0 \pm 0.6$ & $9.4 \pm 1.0$ \\
\hline
\end{tabular}

Table 3. Height of upper lip based on gender and age group.

\begin{tabular}{ccccccc}
\hline \multirow{2}{*}{ Indicators } & \multicolumn{3}{c}{$\begin{array}{c}\text { Second Trimester } \\
\mathbf{M} \pm \mathbf{S D}\end{array}$} & \multicolumn{3}{c}{ Third Trimester } \\
$\mathbf{M} \pm \mathrm{SD}$ & \\
\cline { 2 - 7 } & Male & Female & P Value & Male & Female & P Value \\
\hline Weeks & 58 & 59 & & 51 & 50 & \\
Average & $6.0 \pm 0.6$ & $5.9 \pm 0.7$ & 0.401 & $9.4 \pm 1.0$ & $9.5 \pm 0.9$ & 0.300 \\
\hline
\end{tabular}

Based on our evaluation, the size of upper lip prevalence was distributed equally between the second and third trimester (Figure 1).

Table 4 and Table 5 indicated the length of palate based on age and gender. Based on the table the length of palate was recorded as $16.7 \pm 1.8 \mathrm{~mm}$ in the second trimester and $30.7 \pm 2.1 \mathrm{~mm}$ in the third trimester. Once we concluded the length of palate measurements, we evaluated the length of palate based on gender. Our results depicted the following: $16.7 \pm 1.8 \mathrm{~mm}$ for males and $60.6 \pm$ $1.8 \mathrm{~mm}$ for females in the second trimester. As for the third trimester, our results showed the length of the palate for males as $30.5 \pm 2.0 \mathrm{~mm}$ and $30.9 \pm 2.1$ $\mathrm{mm}$ for female in the third trimester. When comparing the length of palate based on the gender in the second and third trimester, results indicated that there was no statistical significance observed between the length of the palate based on the fetuses' gender.

Based on our results, we estimated precisely that the length of the fetal palate was evenly distributed between the second and third trimester (Figure 2).

Table 6 and Table 7 indicate the width of fetal palate based on age and gender groups. Based on our findings, the measurement of the width of the fetal palate was recorded as $13.2 \pm 1.5 \mathrm{~mm}$ in the second trimester and $24.4 \pm 2.9 \mathrm{~mm}$ in the third trimester. Based on our gender estimation, our results indicate the following $13.3 \pm 1.4 \mathrm{~mm}$ for male and $13.2 \pm 1.5$ for female in the second trimester. As for the third trimester, the results state $24.4 \pm 2.9 \mathrm{~mm}$ for male and $24.5 \pm 3.0$ $\mathrm{mm}$ for female in the third trimester. We did not identify any statistical significant differences when comparing the width of the fetal palate between the second and their trimester.

We examined the details of the width of the fetal palate prevalence by age. Our results show that the distribution of the prevalence was equal in both the second and third trimester (Figure 3).

\section{Microstructure and macrostructure of fetal lips and palate}

Table 8 demonstrations the 12 dimensional indicators that were conducted on 34 cadaver's heights of lips, fossa length, bilateral lip side, height of philtrum, mouths width and width of palate. 
Table 4. The length of fetal palate based on age.

\begin{tabular}{ccc}
\hline Indicators & $\begin{array}{c}\text { II Trimester } \\
\mathbf{M} \pm \mathbf{S D}\end{array}$ & $\begin{array}{c}\text { III Trimester } \\
\mathbf{M} \pm \mathbf{S D}\end{array}$ \\
\hline Weeks & 117 & 101 \\
Average & $16.7 \pm 1.8$ & $30.7 \pm 2.1$ \\
\hline
\end{tabular}

Table 5. The length of fetal palate based on age and gender.

\begin{tabular}{ccccccc}
\hline \multirow{2}{*}{ Indicators } & \multicolumn{3}{c}{$\begin{array}{c}\text { II Trimester } \\
\mathbf{M} \pm \mathrm{SD}\end{array}$} & & \multicolumn{3}{c}{$\begin{array}{c}\text { III Trimester } \\
\mathbf{M} \pm \mathrm{SD}\end{array}$} \\
\cline { 2 - 7 } & Male & Female & P Value & Male & Female & P Value \\
\hline Weeks & 58 & 59 & & 51 & 50 & \\
Average & $16.7 \pm 1.8$ & $16.6 \pm 1.8$ & 0.760 & $30.5 \pm 2.0$ & $30.9 \pm 2.1$ & 0.397 \\
\hline
\end{tabular}

Table 6. Width of palate ( $\mathrm{mm})$ by age group.

\begin{tabular}{ccc}
\hline Indicator & $\begin{array}{c}\text { II Trimester } \\
\mathbf{M} \pm \mathbf{S D}\end{array}$ & $\begin{array}{c}\text { III Trimester } \\
\mathbf{M} \pm \mathbf{S D}\end{array}$ \\
\hline Weeks & 117 & 101 \\
Average & $13.2 \pm 1.5$ & $24.4 \pm 2.9$ \\
\hline
\end{tabular}

Table 7. Width of palate $(\mathrm{mm})$ by gender and age.

\begin{tabular}{ccccccc}
\hline \multirow{2}{*}{ Indicator } & \multicolumn{3}{c}{$\begin{array}{c}\text { II Trimester } \\
\mathbf{M} \pm \mathrm{SD}\end{array}$} & & \multicolumn{3}{c}{$\begin{array}{c}\text { III Trimester } \\
\mathbf{M} \pm \mathrm{SD}\end{array}$} \\
\cline { 2 - 7 } & Male & Female & P Value & Male & Female & P Value \\
\hline Weeks & 58 & 59 & & 51 & 50 & \\
Average & $13.3 \pm 1.4$ & $13.2 \pm 1.5$ & 0.821 & $24.4 \pm 2.9$ & $24.5 \pm 3.0$ & 0.802 \\
\hline
\end{tabular}

Table 8. Structural indicators of fetal lips and palate in the second and third trimesters $(\mathrm{mm})$.

\begin{tabular}{cccc}
\hline & & \multicolumn{2}{c}{ Trimesters } \\
\cline { 3 - 4 } № & Quantity & II & III \\
\cline { 3 - 4 } & Indicators & $\mathbf{1 8}$ & M \\
\cline { 3 - 4 } & & \multicolumn{2}{c}{ SD } \\
\hline 1 & Height of upper lip & $6.1 \pm 1.1$ & $9.8 \pm 1.6$ \\
2 & Right height of upper lip & $5.3 \pm 1.0$ & $8.3 \pm 1.2$ \\
3 & Left height of upper lip & $5.3 \pm 1.0$ & $8.3 \pm 1.2$ \\
4 & Length of fossa & $4.6 \pm 0.8$ & $7.1 \pm 1.2$ \\
5 & Width of fossa & $2.6 \pm 0.5$ & $3.6 \pm 0.6$ \\
6 & Right lateral height of fossa & $4.7 \pm 0.8$ & $6.8 \pm 1.5$ \\
7 & Left lateral height of fossa & $4.7 \pm 0.8$ & $6.8 \pm 1.5$ \\
8 & Height of philtrum & $3.4 \pm 0.4$ & $4.4 \pm 0.7$ \\
9 & Height of philtrum & $3.4 \pm 0.4$ & $4.4 \pm 0.7$ \\
10 & Width of mouth & $178.3 \pm 3.8$ & $191.3 \pm 3.2$ \\
11 & Length of Palate & $20.6 \pm 2.5$ & $35.6 \pm 3.3$ \\
12 & Width of Palate & $17.4 \pm 1.9$ & $29.3 \pm 3.5$ \\
\hline
\end{tabular}




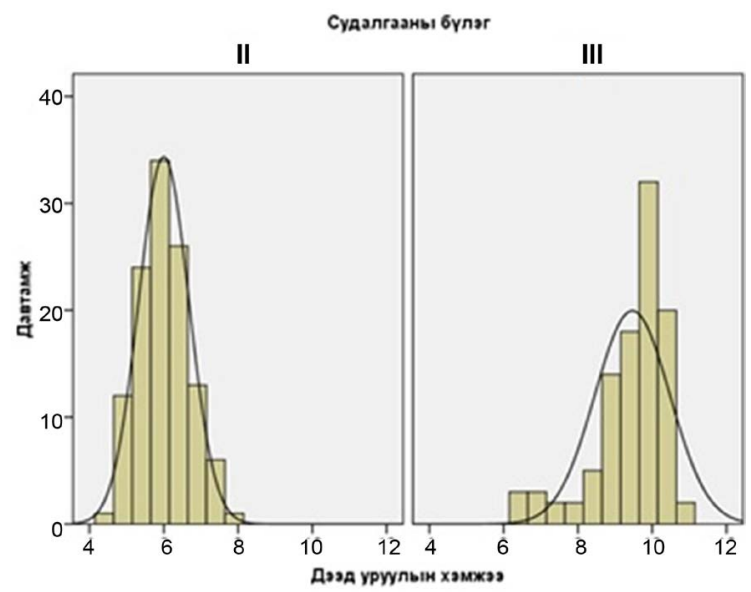

Figure 1. The Prevalence of upper lip size based on age group.

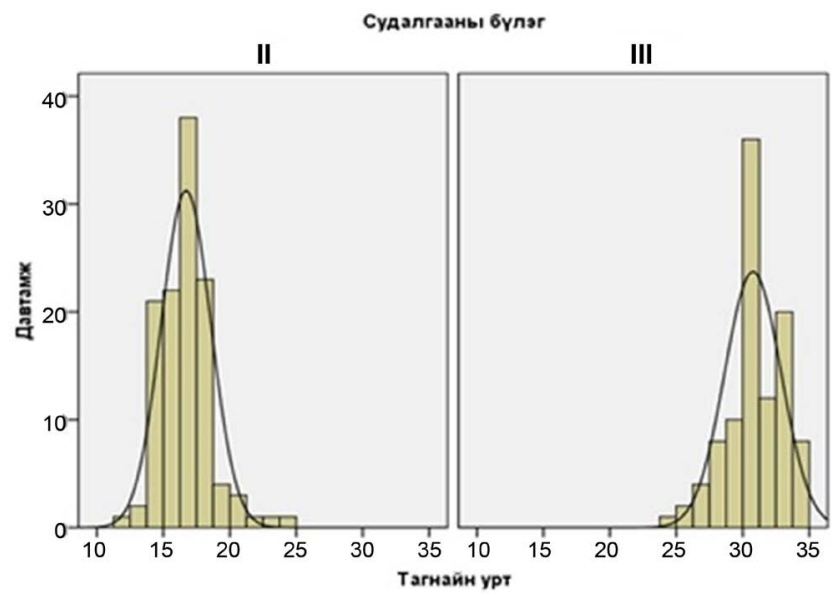

Figure 2. Length of fetal palate's by prevalence group (age and gender).

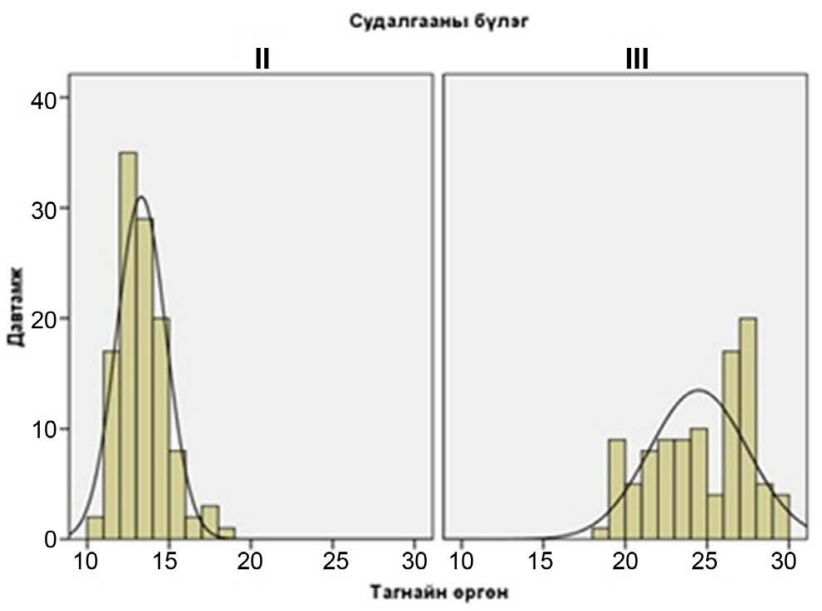

Figure 3. Prevalence of fetal palate width by age $(\mathrm{mm})$.

Our findings determined that the height of the upper lip was $6.1 \pm 1.1 \mathrm{~mm}$ in the second trimester and $9.8 \pm 1.0 \mathrm{~mm}$ in the third trimester. Height of right and left lateral upper lip was $5.3 \pm 1.0 \mathrm{~mm}$ in the second trimester and $8.3 \pm 1.2 \mathrm{~mm}$ 
in the third trimester. The results indicate that the width of philtrum was $4.6 \pm$ $0.8 \mathrm{~mm}$ in the second trimester and $7.1 \pm 1.2 \mathrm{~mm}$ in the third trimester. As for the length of philtrum, our results indicated that the length of the philter in the second trimester was $2.6 \pm 0.8 \mathrm{~mm}$ and $3.6 \pm 0.6 \mathrm{~mm}$ in the third trimester. Laterally, the length of upper lip was $4.7 \pm 0.8 \mathrm{~mm}$ in the second trimester and $6.8 \pm$ $1.5 \mathrm{~mm}$ in the third trimester. Looking at the height difference between the upper and lower lip, our results report $3.4 \pm 0.4 \mathrm{~mm}$ in the second trimester and 4.4 $\pm 0.7 \mathrm{~mm}$ in the third trimester. Assessing the width of the mouth, our findings show the following measurement: $178.3 \pm 3.8$ in the second trimester and 191.3 $\pm 32 \mathrm{~mm}$ in the third trimester. As for the width of palate, we measured the palate to be $20.5 \pm 2.5 \mathrm{~mm}$ in the second trimester and $35.6 \pm 3.3 \mathrm{~mm}$ in the third trimester. Lastly, when observing the length of palate our measurements indicated, $17.4 \pm 1.9 \mathrm{~mm}$ in the second trimester and $29.3 \pm 3.5 \mathrm{~mm}$ in the third trimester.

\section{Microstructure of fetal lips and palate in the Second trimester}

We examined micro preparations on 8 fetal cadaver's hard and soft lips and palate in the second trimester (Table 9).

The Keratinized Squamous epithelium of the skin in the upper lip resulted to 26.2 \pm 5.0 in the second trimester and the non-keratinized squamous epithelium of the mucous membrane was $51 \pm 12.3 \mathrm{~mm}$. The muscular membrane $567.4 \pm 31.1 \mathrm{mkm}$ was $567.4 \pm 31.1 \mathrm{~mm}$. The lips and gland ratio were $73.2 \pm 11.1 \times 129 \pm 19.1 \mathrm{~mm}$.

Table 10 looks at the micro structure of a hard palate, our results showed that the size of cartilage was $243.3 \pm 37 / 2 \mathrm{~mm}$, the palate gland ratio was $163.7 \pm 11.3$ $\times 168.8 \pm 38.1 \mathrm{~mm}$ and the Non-Keratinized Squamous epithelium of hard palate skin was $33.8 \pm 8.9 \mathrm{~mm}$ in the second trimester.

On the other hand, when observing the characteristics of micro-structure of soft palate in the Second Trimester $(\mathrm{mkm})$, our results indicate the following: $589 \pm 29.7 \mathrm{mkm}$ muscular tunic, $113.2 \pm 20.1 \times 155.7 \pm 23.6 \mathrm{mkm}$ palate gland ratio, and $28.8 \pm 5.0 \mathrm{~mm}$ Non-Keratinized Squamous epithelium of the soft palate in the second trimester (Table 11).

According to our study on the micro-structure of lip in 15.3 weeks during

Table 9. The Micro-Structure characteristics of fetus' lips in the second trimester.

\begin{tabular}{ccccccc}
\hline \multirow{2}{*}{ Trimester } & \multicolumn{2}{c}{$\begin{array}{c}\text { Number } \\
\text { of Weeks }\end{array}$} & $\begin{array}{c}\text { Keratinized Stratified Non-Keratinized } \\
\text { tissue of Skin }\end{array}$ & $\begin{array}{c}\text { Muscular } \\
\text { of mucous }\end{array}$ & \multicolumn{2}{c}{ Lip glands } \\
\cline { 3 - 7 } & & & \multicolumn{2}{c}{ M \pm SD } & Height & Width \\
\hline II & 18 & $26.2 \pm 5.0$ & $51 \pm 12.3$ & $567.4 \pm 31.1$ & $73.2 \pm 1.1$ & $129.4 \pm 19.1$ \\
\hline
\end{tabular}

Table 10. The characteristics of Micro-Structure of hard palate in the second trimester.

\begin{tabular}{cccccc}
\hline & & \multicolumn{3}{c}{ Hard Palate } \\
\cline { 3 - 5 } Trimesters & $\begin{array}{c}\text { Number of } \\
\text { Weeks }\end{array}$ & $\begin{array}{c}\text { Non-Keratinized Stratified } \\
\text { Epithelial tissue }\end{array}$ & Cartilage & Palate Glands \\
\cline { 3 - 6 } \cline { 3 - 5 } & & & Meight & Width \\
\cline { 3 - 6 } II & 18 & $33.8 \pm 8.9$ & $243.3 \pm 37.2$ & $163.7 \pm 11.3$ & $168.8 \pm 38.1$ \\
\hline
\end{tabular}


Table 11. The characteristics of Micro-Structure of soft palate in the second trimester $(\mathrm{mkm})$.

\begin{tabular}{cccccc}
\hline & & \multicolumn{4}{c}{ Soft Palate } \\
\cline { 3 - 6 } Trimester & $\begin{array}{c}\text { Number of } \\
\text { Weeks }\end{array}$ & $\begin{array}{c}\text { Non-Keratinized stratified } \\
\text { squamous epithelial tissue }\end{array}$ & $\begin{array}{c}\text { Muscular } \\
\text { Membrane }\end{array}$ & & \multicolumn{2}{c}{ Palate Glands } \\
\cline { 3 - 6 } \cline { 3 - 5 } & & & Height & Width \\
\hline II & 18 & $28.8 \pm 5.0$ & $589 \pm 29.7$ & $113.2 \pm 20.1$ & $155.7 \pm 23.6$ \\
\hline
\end{tabular}

gestation, our research reveals that the skin portion of the mucous membrane and the muscular tunic were clearly distinguishable. In contrast, the multiple layer of the squamous epithelium was not clearly distinguishable. In other words, the squamous epithelium had not developed completely and was therefore not depicted inoperative images. In addition, the non-keratinized stratified squamous epithelium of mucous membrane was also not perceived clearly. Nevertheless, it is evident that the formation and release of gland occur in the mucous membrane. This study was able to observe that the glands production and secretion portion is located in the palate of the mucous membrane. Furthermore, we found that the muscular tunic and muscular fibers were similarly not formed completely. In conclusion, our research implies that we observed a fragmented formation of the platelet on the micro-structure of lip in 15.3 weeks during gestation (Pictures 10-12).

When conducting research on the microstructure of a 20-week fetal's of lips, the mucous, skin, muscular membrane appear to be clearly visible. The five-multilayered keratinized stratified squamous epithelial tissue of lamina in the lip was the same as the borders of the lip, showing no clear visibility. In other words, their images were developed incompletely. On the other hand, the multilayered non-keratinized stratified squamous epithelial tissue structure of lip during 20-week period, was also the same as borders, it was not visible at 15.3-week gestational period. The muscular secretion and exceptional parts of the muscular secretion which is located in the lamina began developing during 20-week of gestational period. The fetal muscular membrane and muscular fibers were not developed. During 15.3 week of gestational period, we observed the development of separated continuous laminae. The muscular membrane and the muscular fiber of a fetal during 20 -week period of gestation developed in the laminae and were jointed with each other around different parts of the lips. At 20-week gestational period, the upper lip process combined with its muscular fibers were thickened and rolled. The mucous membrane layer of the upper lip borders appeared clearly (Pictures 13-17).

On the other hand, looking at the microstructure of 26-weeks old fetal's lips, the mucous and muscular membrane were visible during this period. Whereas a fetal during 20-week fetal lips, the epithelial tissue of lamina and the multilayer keratinized stratified epithelial tissue layers were not visible at the 20 -week period. In comparison to the 26 weeks, the mucous and muscular membrane were 


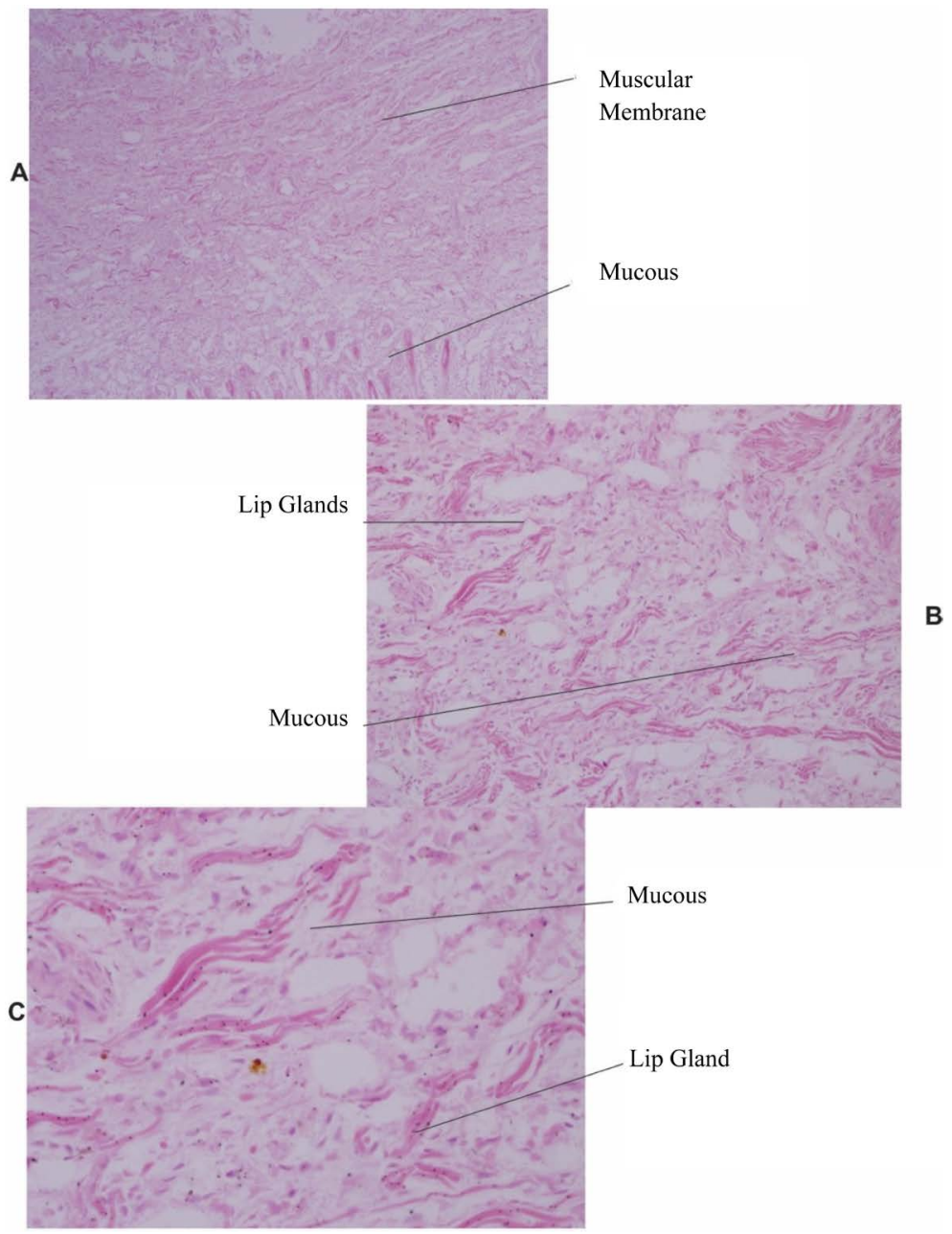

Picture 10. Microstructure of the upper lip during 15.3 weeks of gestational period.
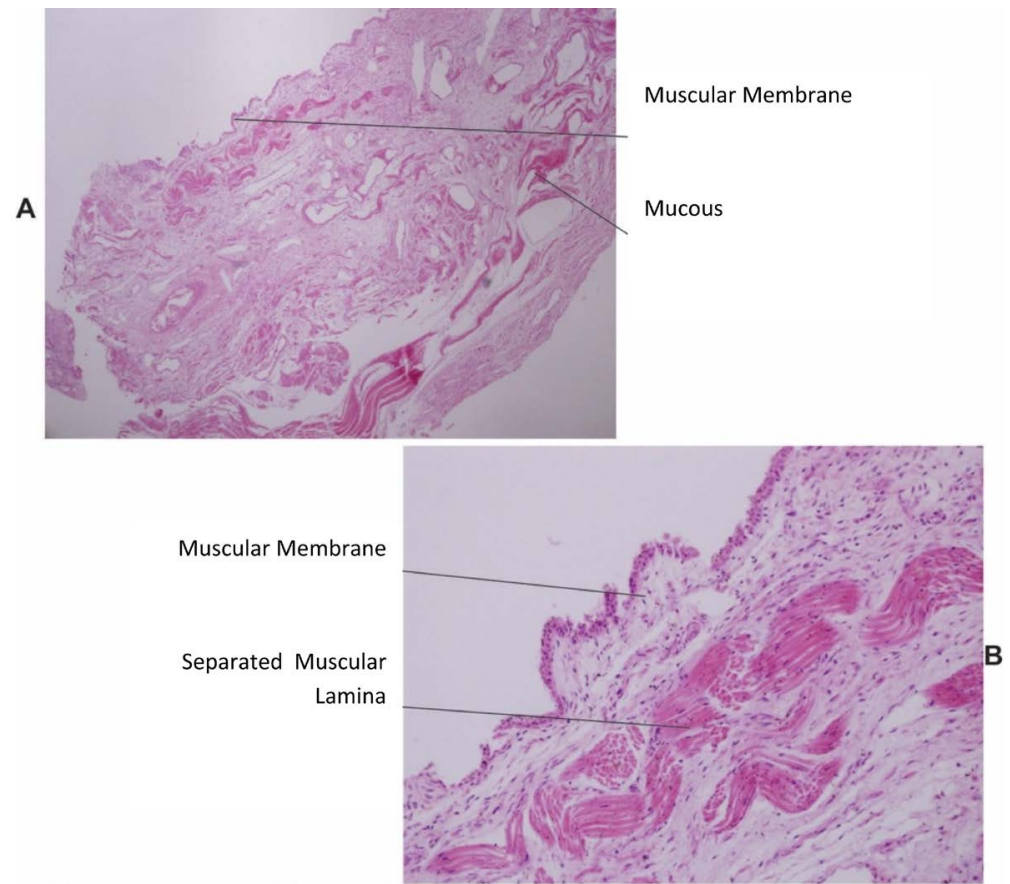


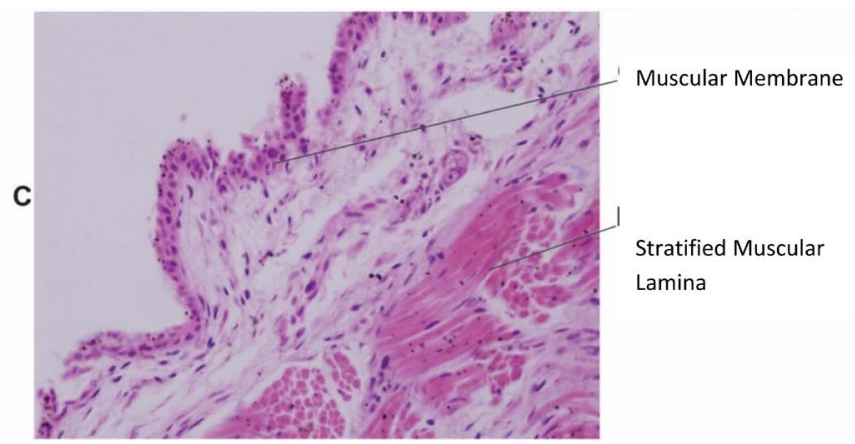

Picture 11. Microstructure of the upper lip during 15.3-weeks of gestational period.

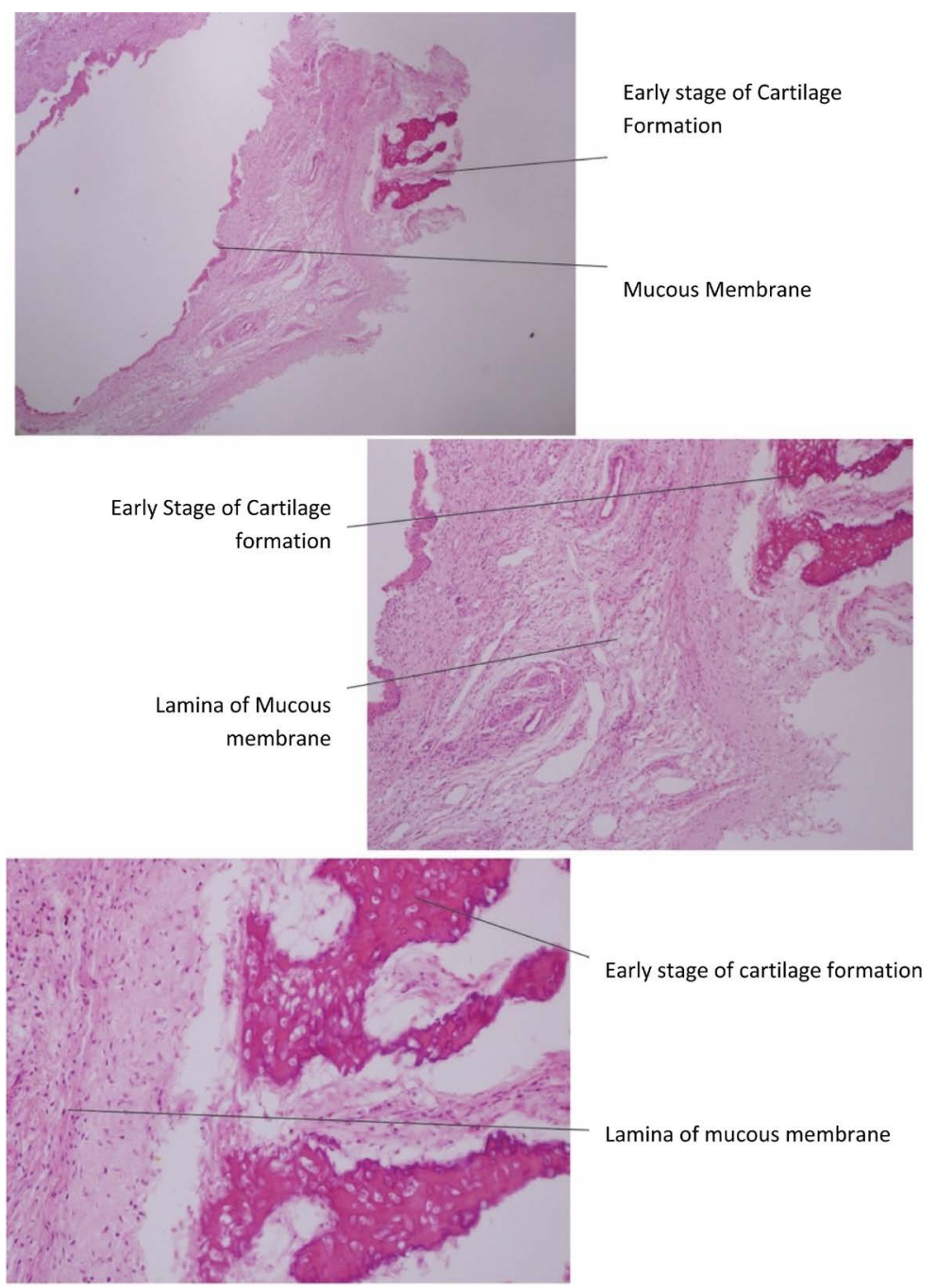

Picture 12. Microstructure of hard palate during 15.3 weeks of gestational period.

visible while we conducted our research. When we took a look at the 26-week fetal lips mucous and its multilayer non-keratinized stratified epithelial tissue structure compared to the 20-week fetal's mucous membrane, multilayer non-keratinized stratified squamous tissue structure, the boarder layers were also visible. 

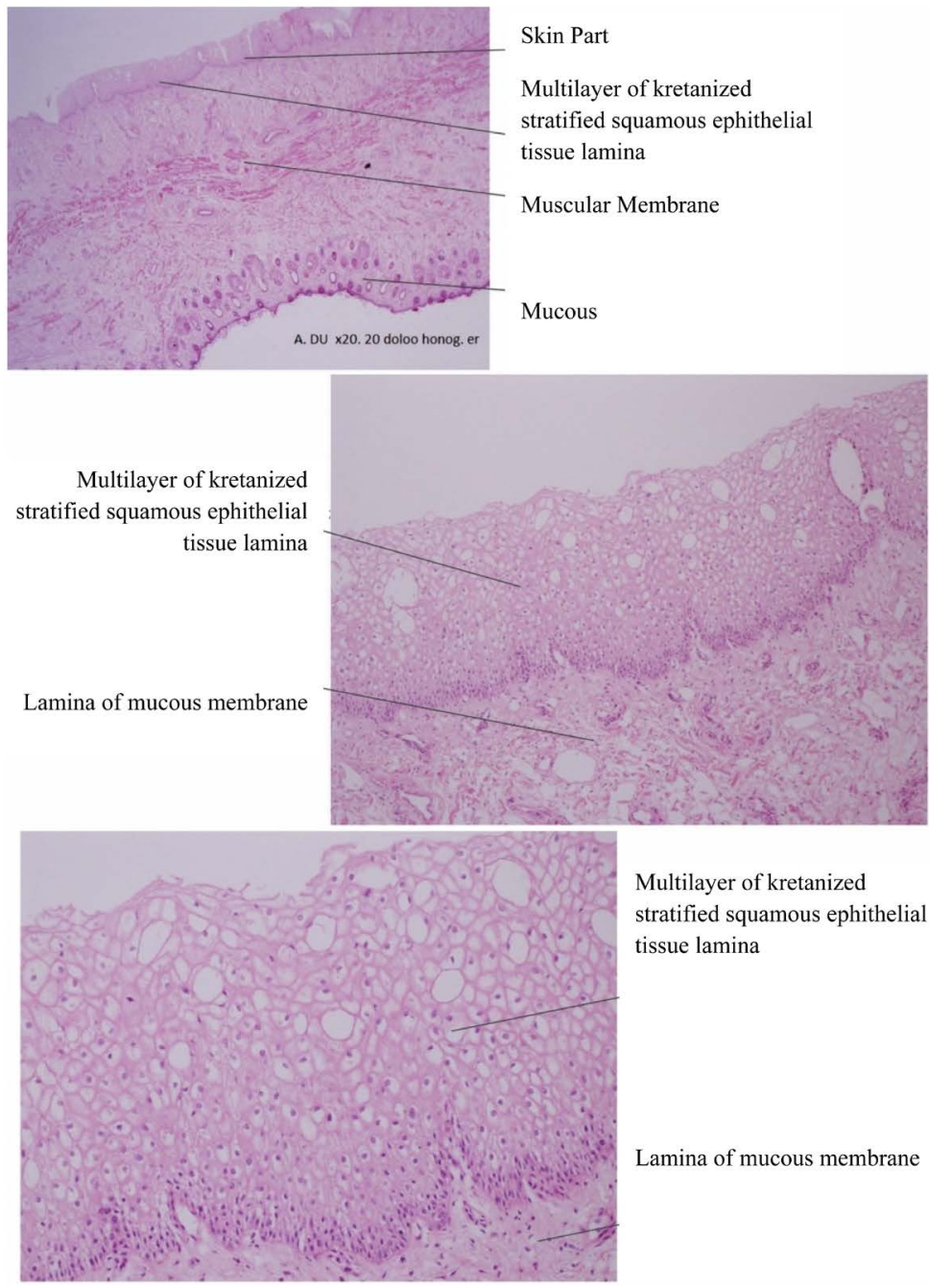

Picture 13. Micro-structure of the upper lip during the 20-week period of gestational.

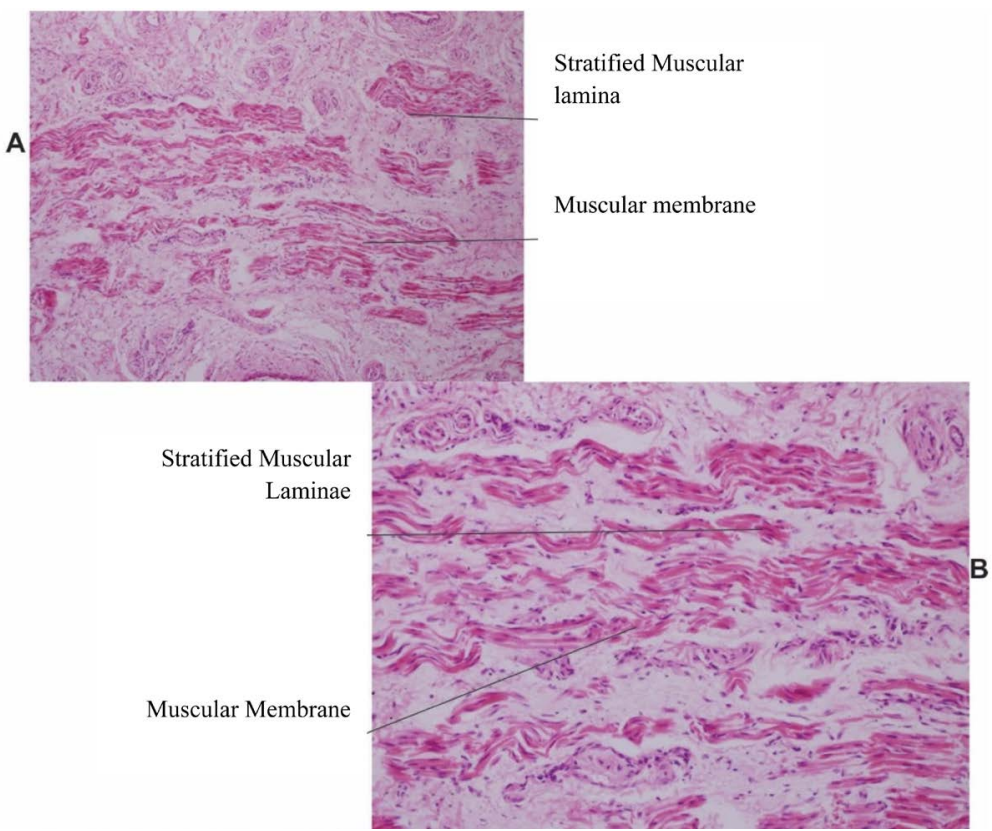




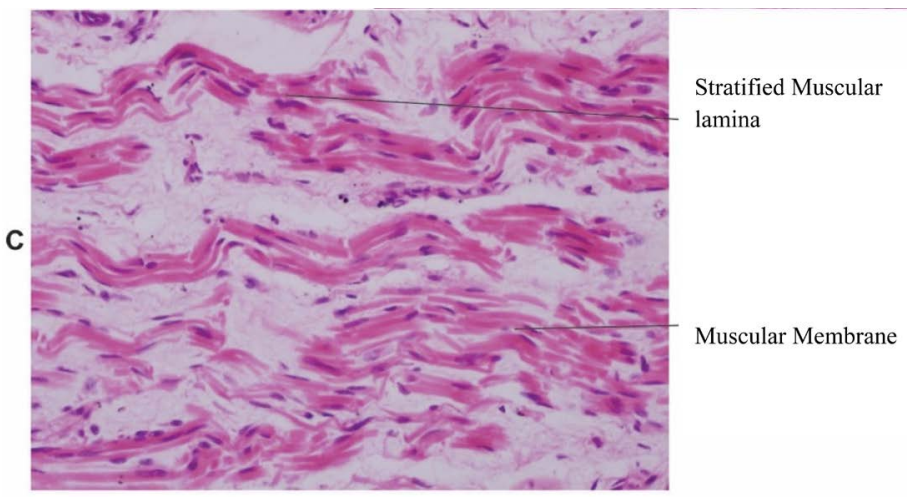

Picture 14. Microstructure of muscular membrane of upper lip during 20-week gestational period.

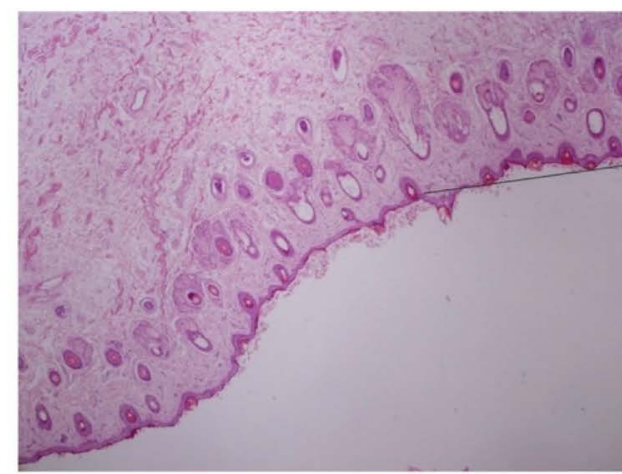

Early stage of lip glands

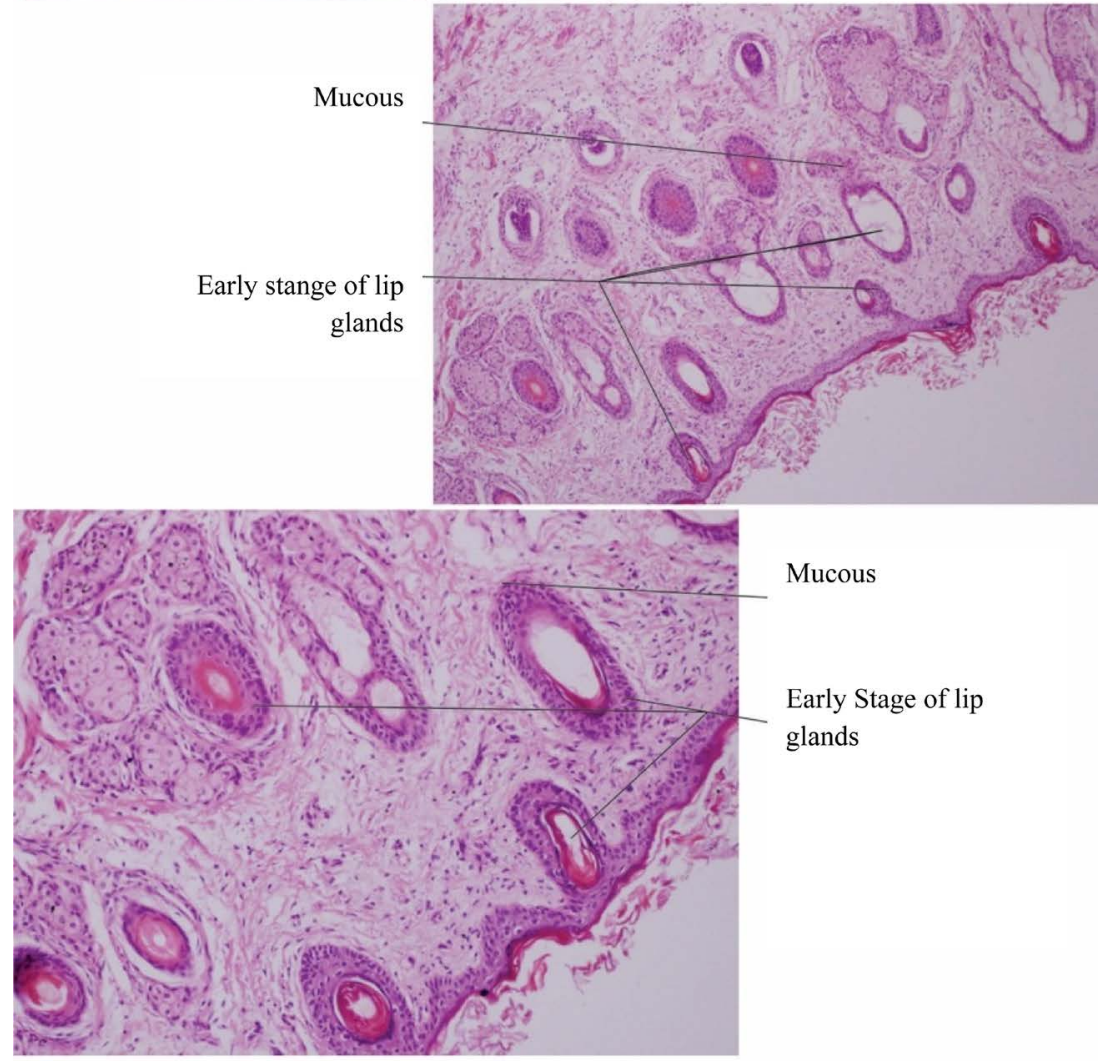

Picture 15. Microstructure of mucous of upper lip during 20 weeks of gestational period долоо хоногтой. 

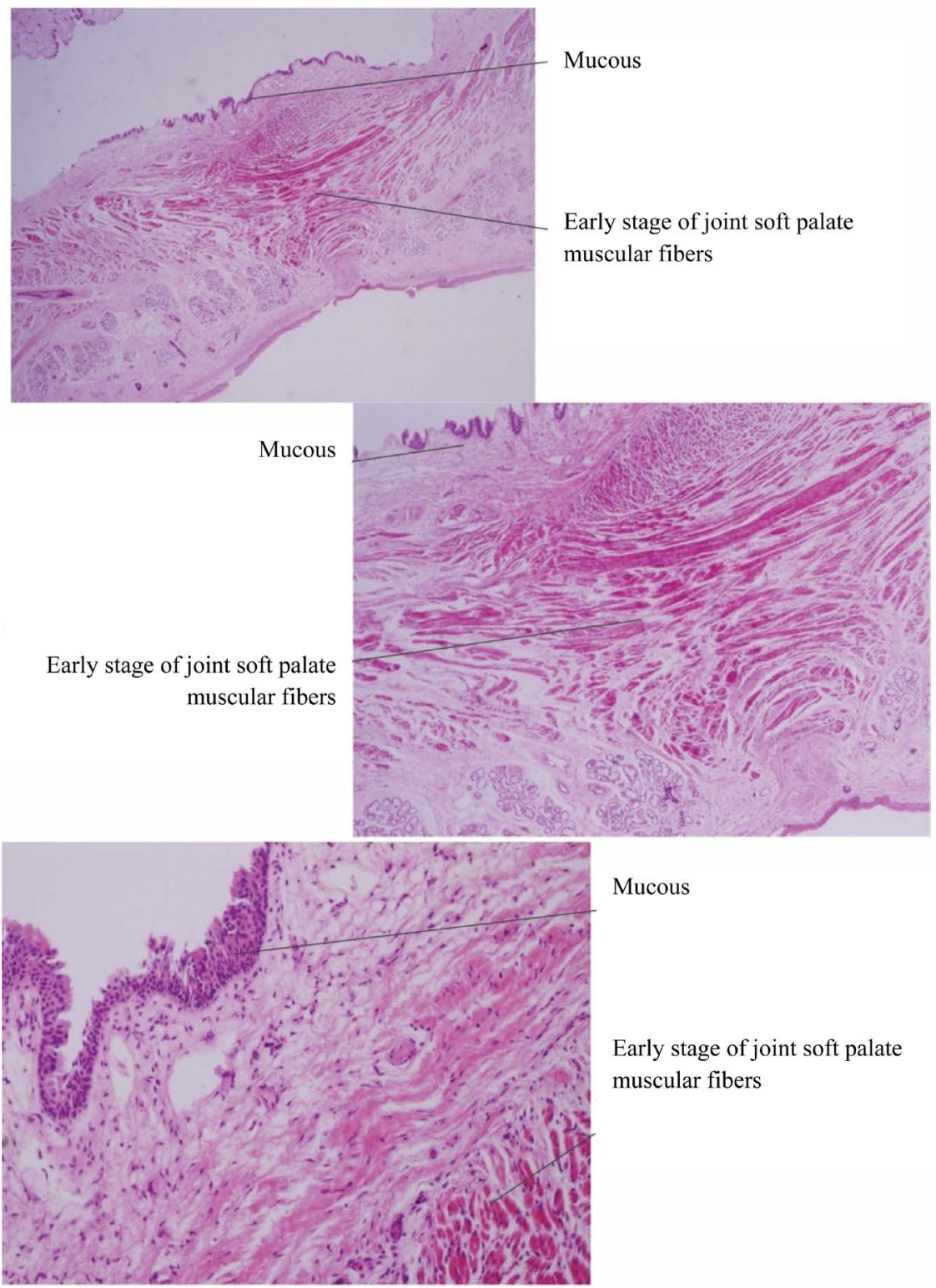

Mucous

Early stage of joint soft palate muscular fibers

Picture 16. Microstructure of soft palate during 20 weeks of gestational period.

Once the glands excretion of mucous membrane began, the excreational parts of the lips were jointed completely. As a result, we can conclude that there was a positive development in excreational and endocrinal formation. The fetals lip during 20-week of gestation, indicated that the muscular membrane and muscular fibers of lamina were joint successfully in some locations. As for the 26-week fetal, the muscular membrane and muscular fiber laminae were join completely without any separation. The muscular secretion and endocrinal portions which are located in the lamina, showed that some portions of the lips were developed well during 26-week of gestational period as opposed to 20 -week of gestational period. This indicates that the muscular membrane has effectively formed during the 26-week fetal in comparison to a fetal during 20-week of gestation (Pictures 18-20). 


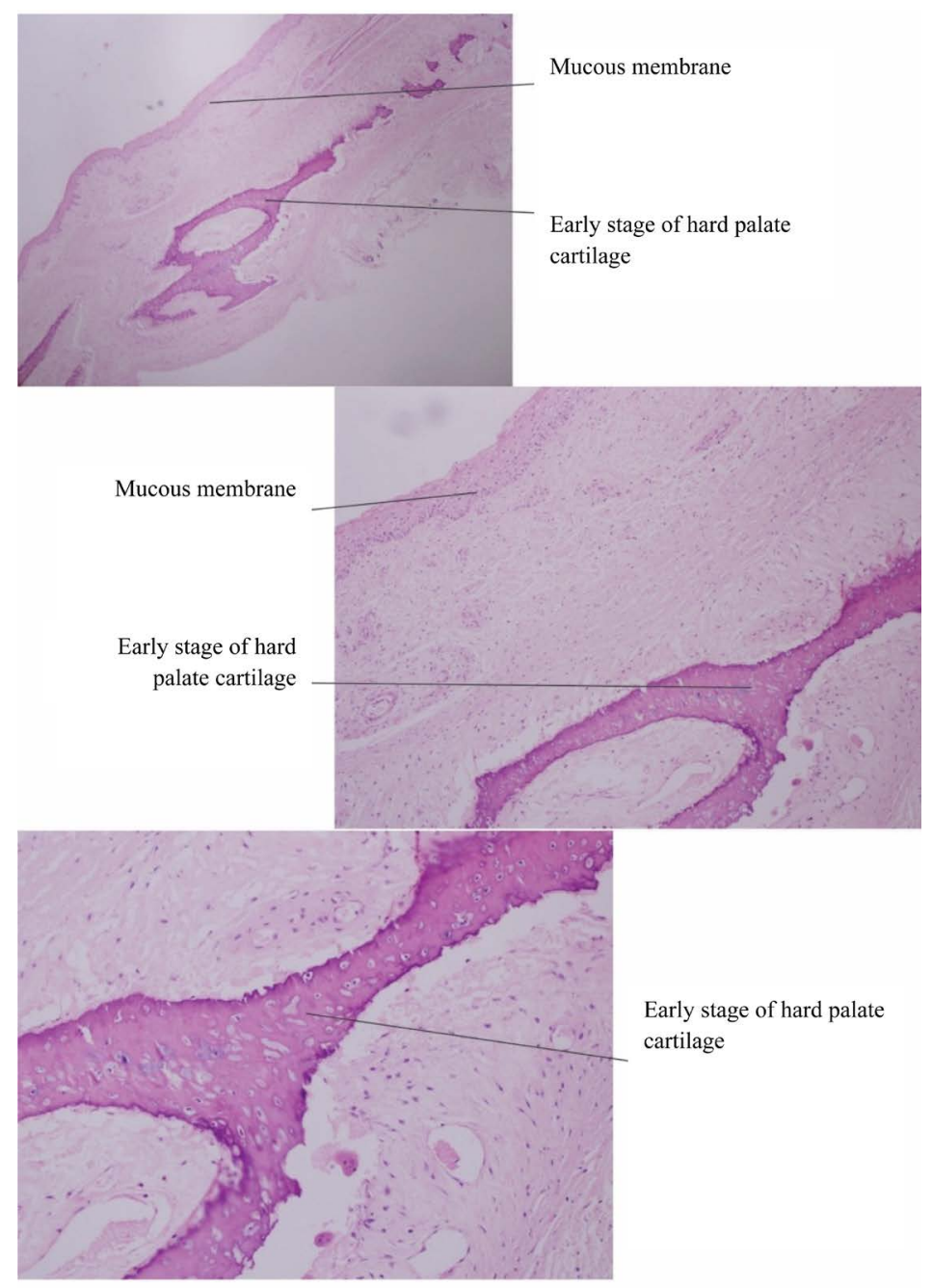

Picture 17. Microstructure of hard palate during week 20 of gestational period.

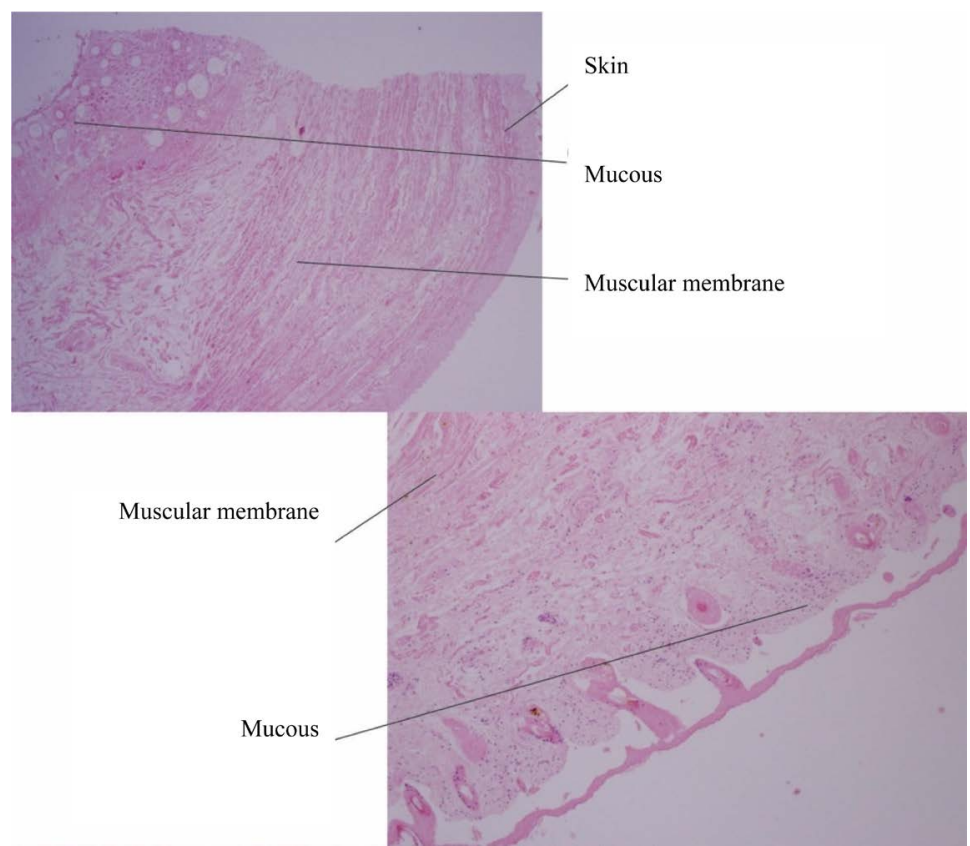




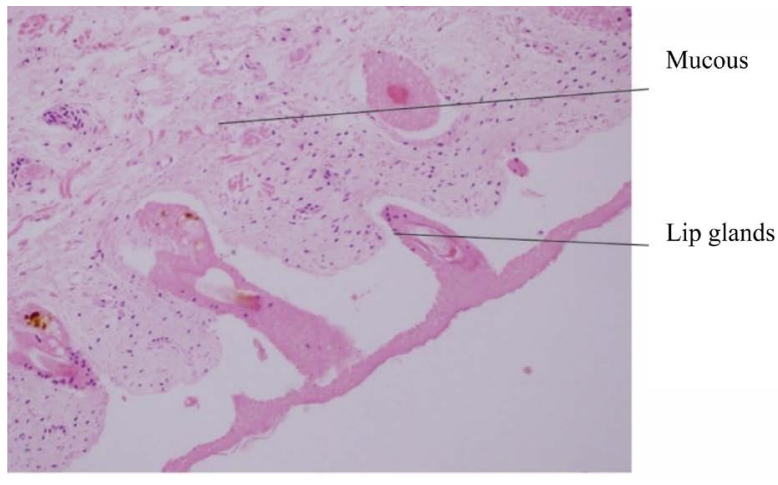

Picture 18. Microstructure of upper lip during week 26 of gestational period.

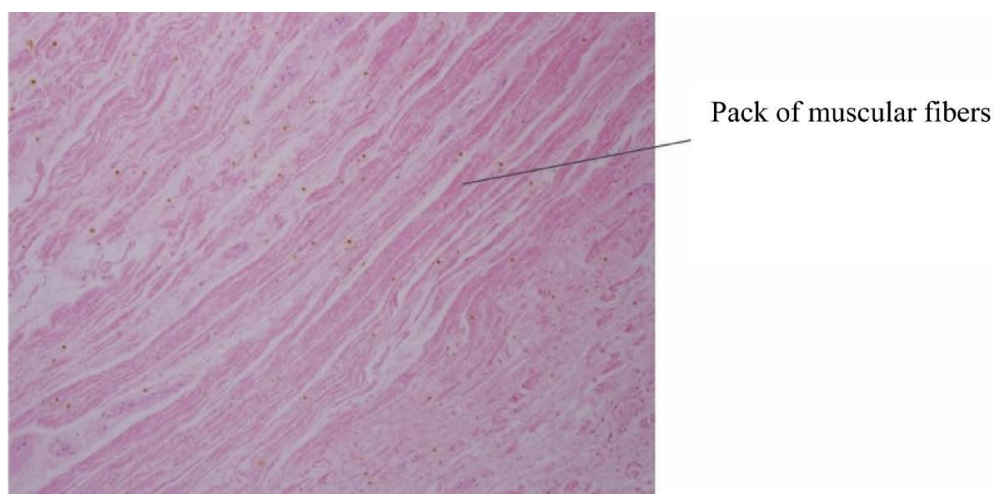

Pack of muscular fibers
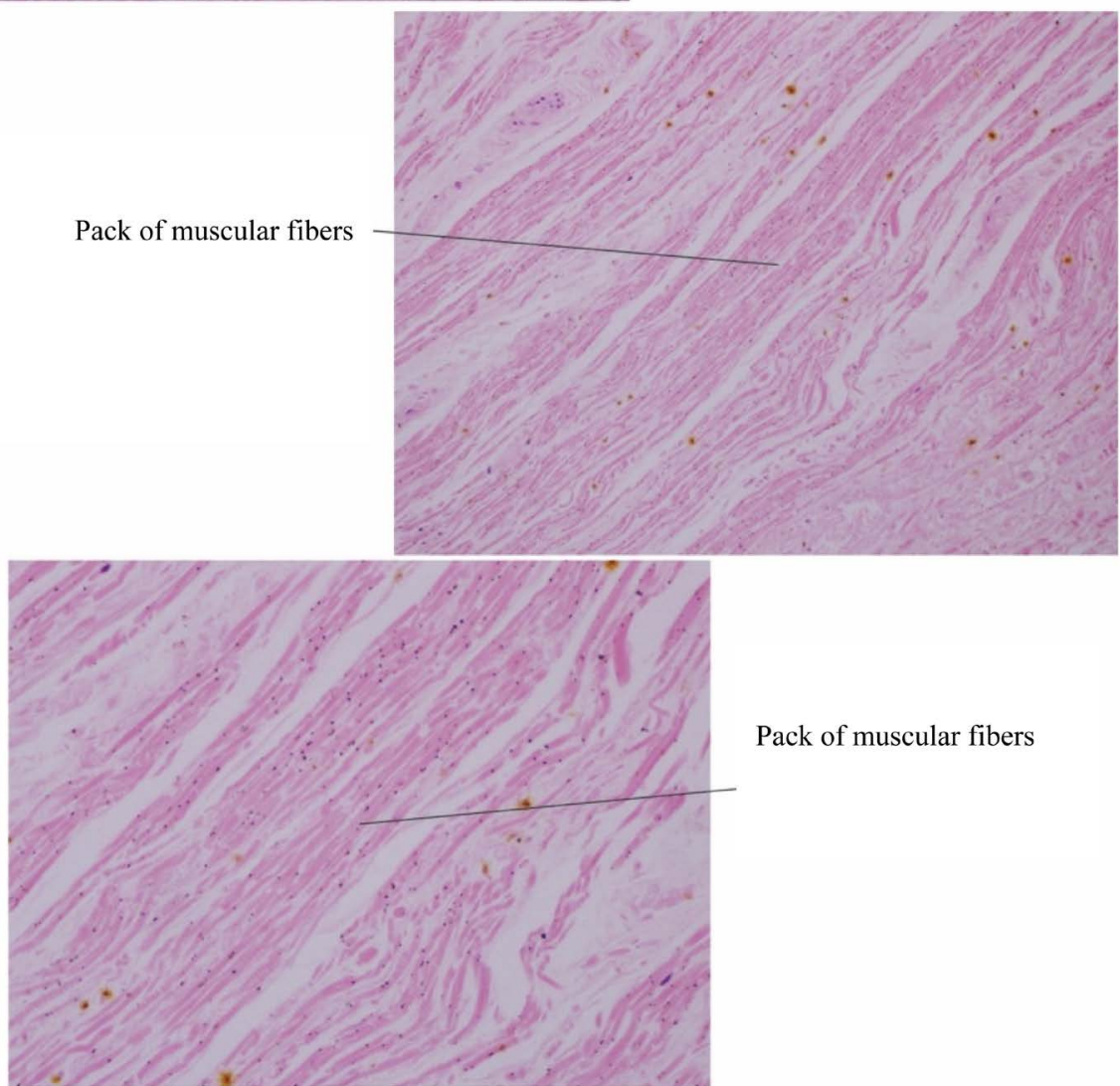

Pack of muscular fibers

Picture 19. Microstructure of muscular membrane of upper lips during week 26 of gestational period. 


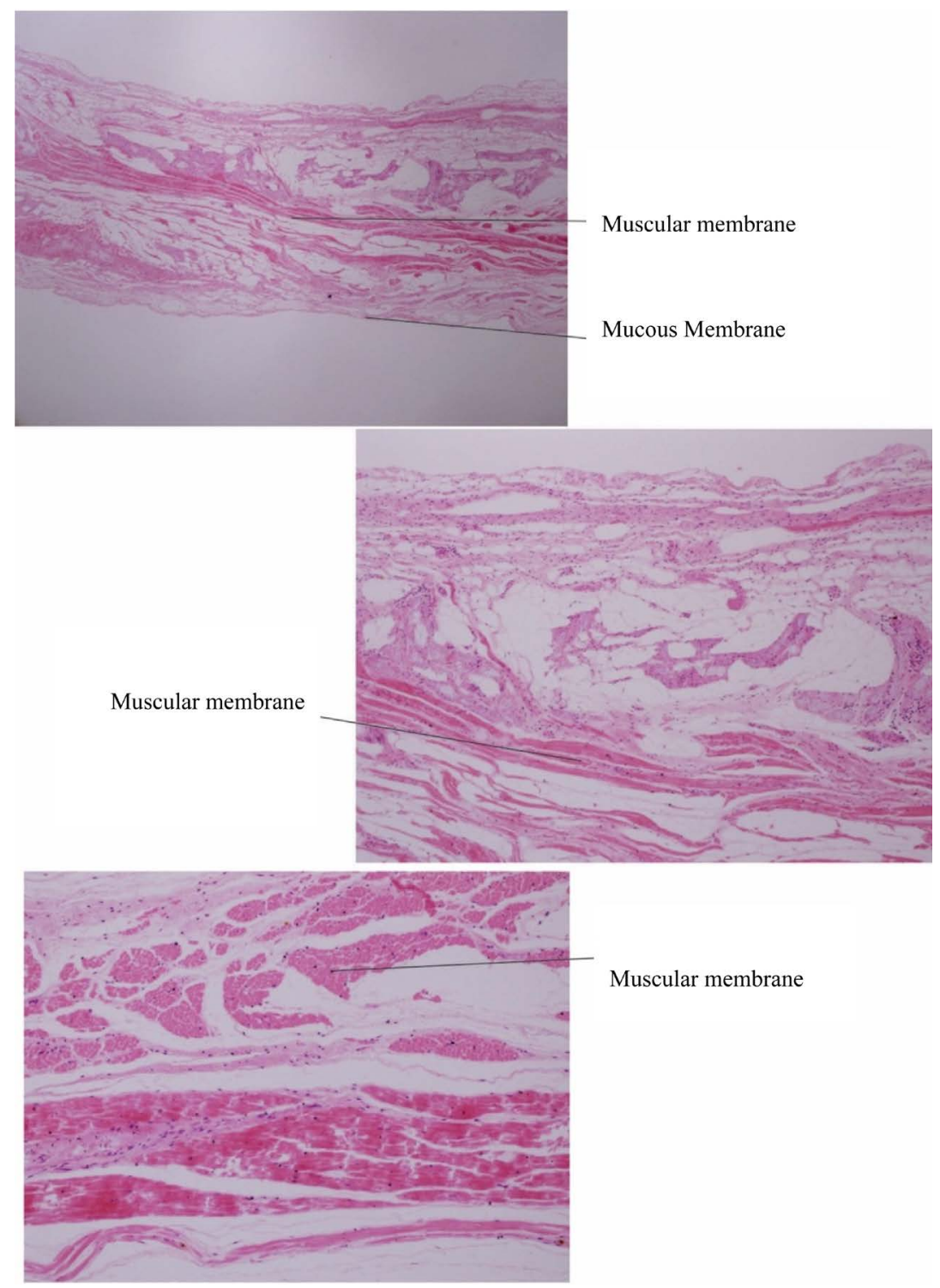

Picture 20. Microstructure of soft palate during week 26 of gestational period.

\section{Results of microstructure of fetal lip and pate in the III Trimester}

We examined 26 fetal' slips and hard palate and its preparation structure in the third trimester (Table 12).

Based on our studies, our results show that keratinized stratified squamous epithelial tissue of upper lip was $74.2 \pm 21.6 \mathrm{mkm}$ in the third trimester. While the non-keratinized stratified squamous epithelial tissue of mucous was $28.7 \pm$ $9.7 \mathrm{mkm}$. As for the muscular membrane, we found that the glands ratio was 103 $\pm 15.0 \times 135 \pm 17.6 \mathrm{mkm}$ for the microstructure of lips for a16-week fetal (Table 13).

Non-Keratinized stratified epithelial tissue of hard plate was $30.3 \pm 7.9 \mathrm{mkm}$ in the third trimesters. The size of cartilage was $586.9 \pm 12.0 \mathrm{mkm}$, and the palate gland ration was $104.5 \pm 11.3 \times 136.2 \pm 16.6 \mathrm{mkm}$ for 16 -week fetal hard palate (Table 14). 
Table 12. Microstructure indicators of fetal lip in the III trimester (mkm).

\begin{tabular}{ccccccc}
\hline \multirow{2}{*}{ Trimester } & \multicolumn{2}{c}{$\begin{array}{c}\text { Keratinized } \\
\text { of Week }\end{array}$} & $\begin{array}{c}\text { Non-Keratinized } \\
\text { stratified squamous } \\
\text { epithelial tissue }\end{array}$ & $\begin{array}{c}\text { stratified epithelial } \\
\text { tissue of mucous }\end{array}$ & $\begin{array}{c}\text { Muscular } \\
\text { Membrane }\end{array}$ & \multicolumn{2}{c}{ Lip Gland } \\
\cline { 3 - 7 } & & \multicolumn{4}{c}{ M SD } \\
\hline III & 16 & $74.2 \pm 21.6$ & $28.7 \pm 9.7$ & $135 \pm 17.6$ & $103 \pm 15.0$ & $135 \pm 17.6$ \\
\hline
\end{tabular}

Table 13. Microstructure Indicators of fetal hard palate in the III trimester (mkm).

\begin{tabular}{|c|c|c|c|c|c|}
\hline \multirow{4}{*}{ Trimester } & \multirow{4}{*}{$\begin{array}{l}\text { Number of } \\
\text { weeks }\end{array}$} & \multicolumn{4}{|c|}{ Hard palate } \\
\hline & & \multirow{2}{*}{$\begin{array}{l}\text { Non-Keratinized stratified } \\
\text { squamous epithelial tissue }\end{array}$} & \multirow{2}{*}{ Cartilage } & \multicolumn{2}{|c|}{ Palate gland } \\
\hline & & & & Height & Width \\
\hline & & \multicolumn{4}{|c|}{$\mathrm{M} \pm \mathrm{SD}$} \\
\hline III & 16 & $30.3 \pm 7.9$ & $586.9 \pm 12.0$ & $104.5 \pm 11.3$ & $136.2 \pm 16.6$ \\
\hline
\end{tabular}

Table 14. Microstructure indicators of soft plate in the third trimesters (mkm).

\begin{tabular}{|c|c|c|c|c|c|}
\hline \multirow{4}{*}{ Trimesters } & \multirow{4}{*}{$\begin{array}{l}\text { Number of } \\
\text { weeks }\end{array}$} & \multicolumn{4}{|c|}{ Soft Palate } \\
\hline & & \multirow{2}{*}{$\begin{array}{l}\text { Non-keratinized stratified } \\
\text { squamous epithelial tissue }\end{array}$} & \multirow{2}{*}{$\begin{array}{l}\text { Muscular } \\
\text { Membrane }\end{array}$} & \multicolumn{2}{|c|}{ Palate Gland } \\
\hline & & & & Height & Width \\
\hline & & \multicolumn{4}{|c|}{$\mathrm{M} \pm \mathrm{SD}$} \\
\hline III & 16 & $18.8 \pm 4.7$ & $340 \pm 30.7$ & $168.6 \pm 91.2$ & $241.7 \pm 107.2$ \\
\hline
\end{tabular}

Non-Keratinized stratified squamous epithelial tissue of soft palate was $18.8 \pm$ $4.7 \mathrm{mkm}$ in the third trimester. The muscular membrane was $340 \pm 30.7 \mathrm{mkm}$, and the palate gland ratio was $168.6 \pm 91.2 \times 241.7 \pm 107.2 \mathrm{mkm}$.

Based on our research conducted on a fetal during 40 weeks of gestational period, we found that the fetal skin, mucous and muscular membrane were visible. Looking at fetal during week 20 of gestational period, the fetal lips, epithelial tissue of lamina, and the multilayer keratinized stratified epithelial tissue boarded layers were also visible. Whereas at a fetal at the 40 weeks of gestational period was more visible, similar to the lip structure of an adult. When looking at a 40 -week fetal's Non-keratinized stratified squamous epithelial tissues, the boarder layers were more visible compared to the Non-keratinized stratified squamous epithelial tissue structure of a 26-week fetal. The glands excretion which is located in the lamina of mucous membrane excreational and endocrinal portions were joint completely and shows a positive development. This image indicates the connection of muscular fibers without separation of in the 40-week fetal muscular membrane (Pictures 21-23).

\section{Conclusions}

Based on the reserach, we conducted to better understand the micro and macro structure indicators of the cleft of the fetus during the second and third trimester 
A
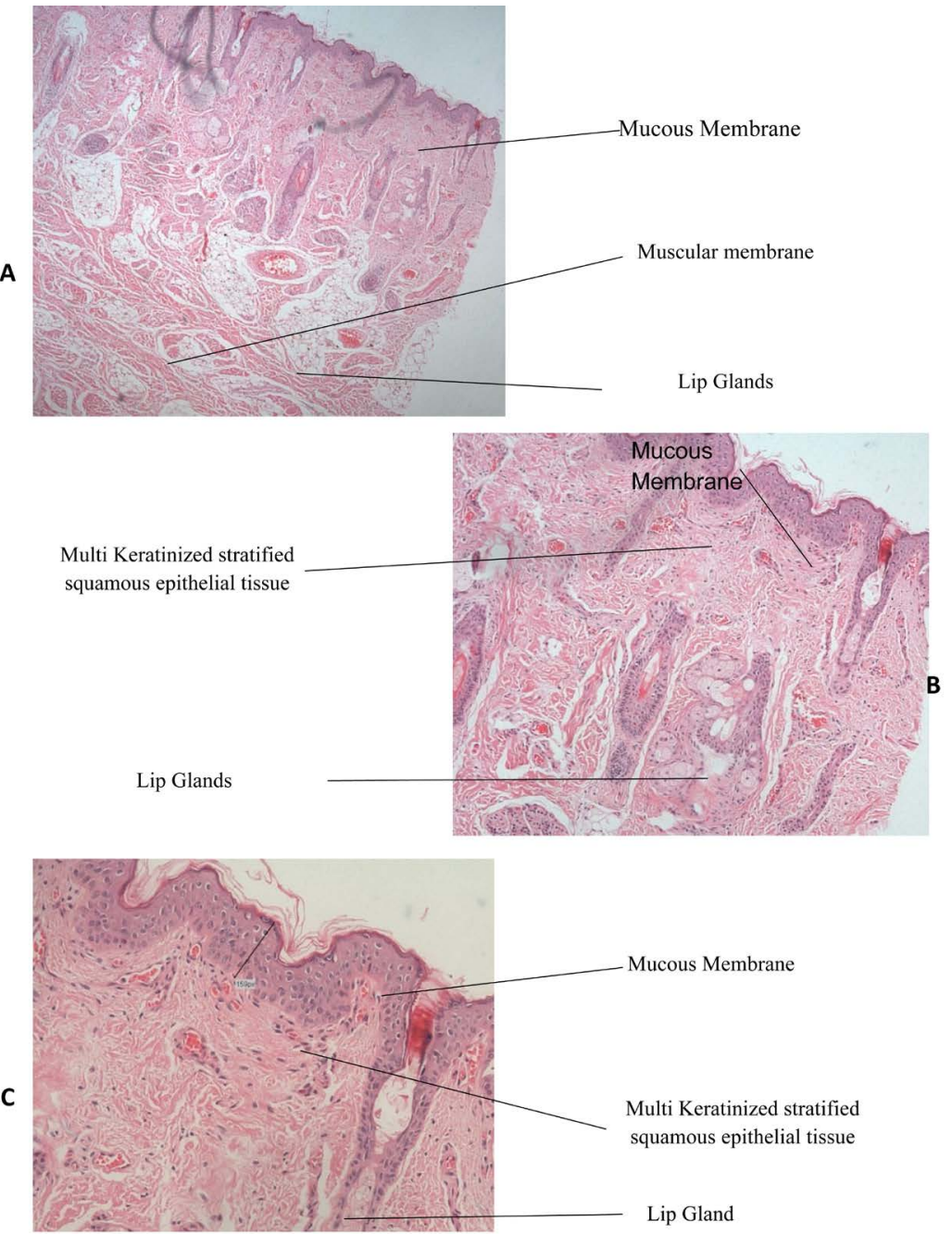

Picture 21. Microstructure of upper lip during week 40 of gestational period.
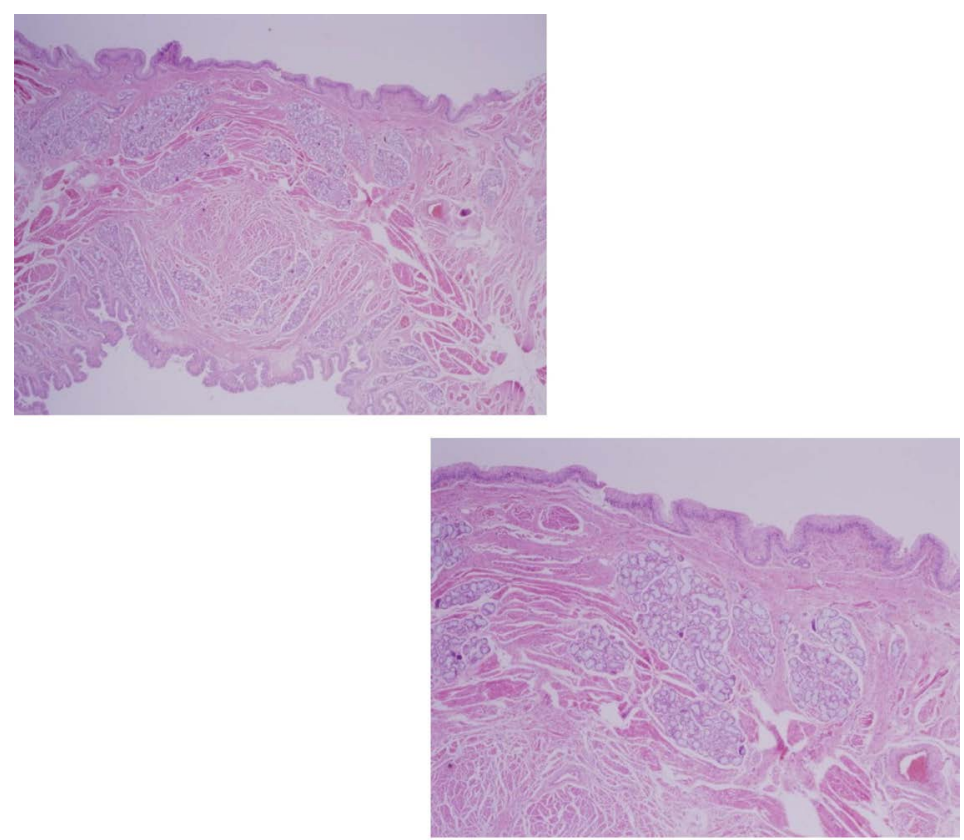


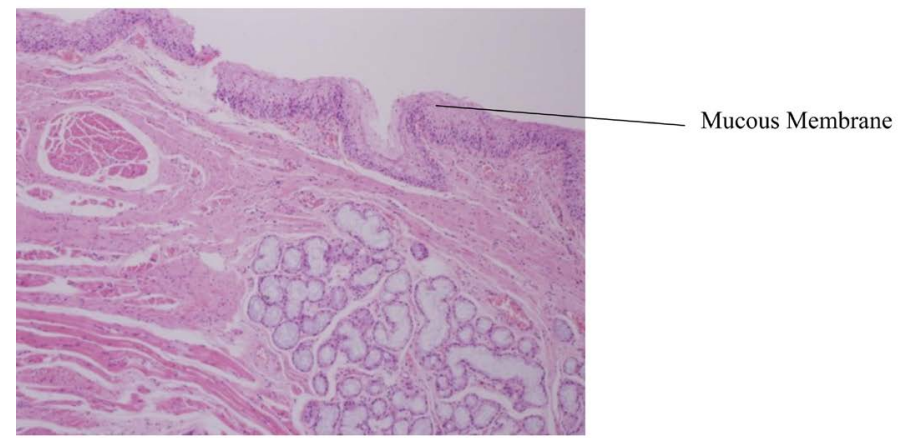

Picture 22. Microstructure of soft palate during week 40 of gestational period.
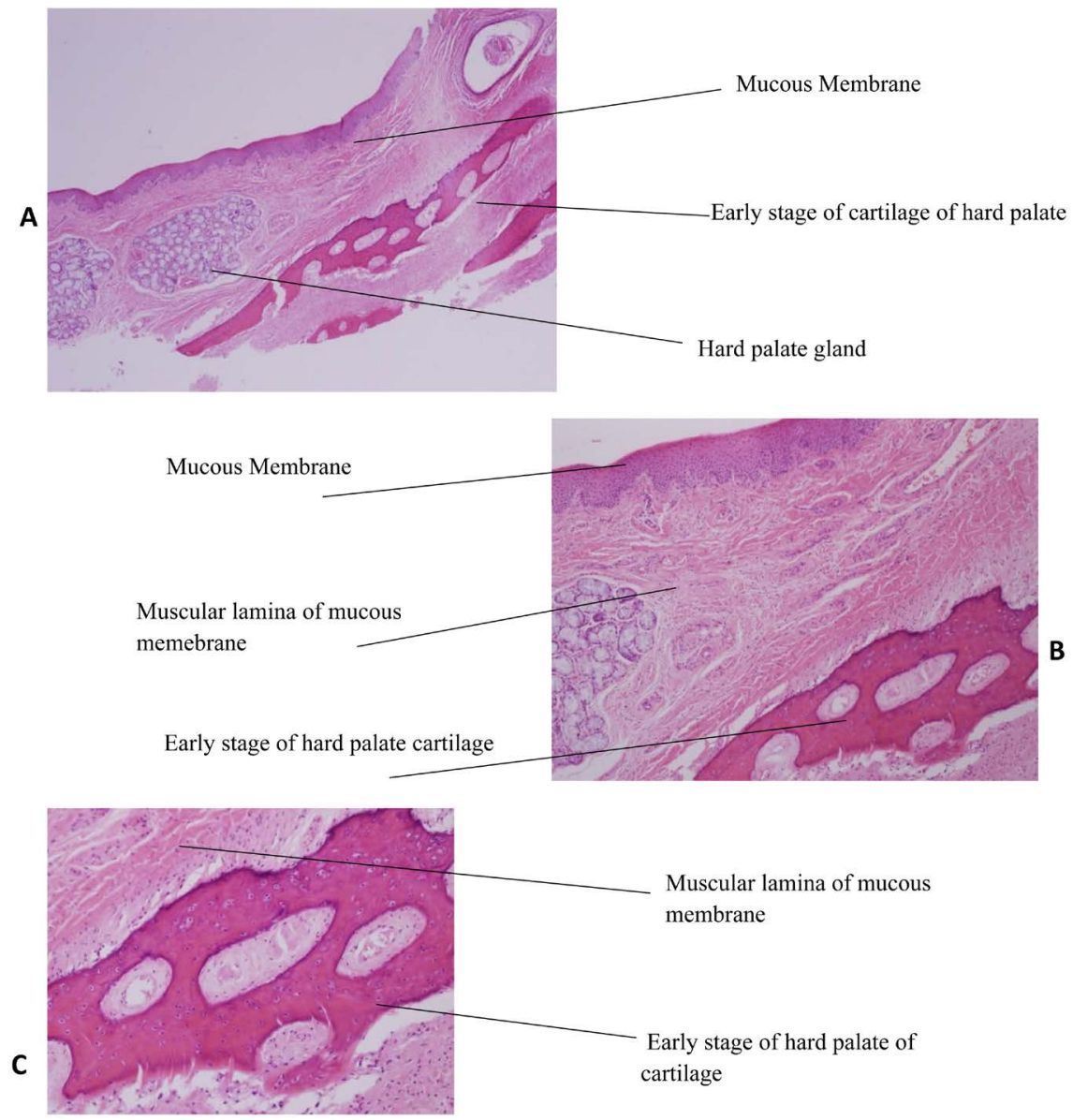

Picture 23. Microstructure of hard palate during week 40 of gestational period.

of the gestational period. We were able to successfully study the specific structure and development of cleft and palate. We have indicated the conclusion made for the development of cleft and palate for each gestational period studied. The implication of this researcher detects the congenital cleft lip and palate in the early stage, evaluates the development of lips and palate and determines morphometry indicator of lip and palate of the fetus.

Week 15.3

According to our study on the micro-structure of lip in 15.3 weeks during 
gestation, our research reveals that the skin portion of the mucous membrane and the muscular tunic was clearly distinguishable. In contrast, multiple layer of squamous epithelium was not clearly distinguishable. In other words, the squamous epithelium was not developed completely and depicted inoperative images. In addition, the Non-Keratinized stratified squamous epithelium of mucous membrane was also not perceived clearly. Nevertheless, it is evident that the formation and release of gland occur in the mucous membrane. This study was able to observe that the glands production and secretion portion is located in the palate of the mucous membrane.

\section{Week 20}

When we conducted research on a 20 -week fetal's microstructure of lips, the mucous, skin, muscular membrane appear to be clearly visible. Five multilayered Keratinized Stratified squamous epithelial tissue of lamina in the lip was the same as the borders of the lip. It was not clearly visible. In other words, their images were developed incompletely. On the other hand, multilayered non-Keratinized Stratified squamous epithelial tissue structure of lip during 20-week period was also the same as borders. It was not visible at 15.3-week gestational period.

\section{Week 26}

We conducted research on 26 weeks fetal microstructure of lips and sink mucous, and muscular membrane was visible during this period. Whereas the fetal during 20-week fetal lips, epithelial tissue of lamina, multilayer keratinized stratified epithelial tissue layers were not visible at the 20 -week period. In comparison to the 26 weeks, the above-mentioned organs were visible while we conducted our research. When we took a look at the 26-week fetal lips mucous, multilayer non-keratinized stratified epithelial tissue structure compared to the 20 -week fetal mucous membrane, multilayer non-keratinized stratified squamous tissue structure, the boarder layers were visible. We conducted research at 19 and 22 weeks of gestational period out of which 58 were males and 59 were females in the second trimesters. In the third trimester, 29 - 32 weeks of gestational period out of which were 51 males and 50 females. During this gestational period, we conducted our research using a $3 \mathrm{D}$ ultra-sonography screening. In the second trimester, gestational period was $20.34 \pm 0.77$ weeks. In the third trimester, the gestational period was $30.84 \pm 0.89$ weeks.

\section{Week 40}

A 40-week fetal Non-Keratinized stratified squamous epithelial tissues boarder layers were more visible compared to Non-Keratinized stratified squamous epithelial tissue structure of a 26 -week fetal.

The glands excretion which is located in the lamina of mucous membrane excreational and endocrinal portions were jointed completely and shows a positive development.

This image indicates the connection of muscular fibers without separation of a 26-week fetal muscular membrane compared to a 40-week fetal muscular membrane.

Overall, we found that the height of fetal upper lip was estimated to $6.0 \pm 0.6$ 
$\mathrm{mm}$ in the second trimester, and in the third trimester it was estimated to $9.4 \pm$ $1.0 \mathrm{~mm}$. In both sexes: in female the fetal upper lip was estimated to $5.9 \pm 0.7$ $\mathrm{mm}$ in second trimester, in male it was $6.0 \pm 0.6 \mathrm{~mm}$ also in second trimester. For the third trimester: in female it was estimated to $9.5 \pm 0.9 \mathrm{~mm}$, in male it was $9.4 \pm 1.0 \mathrm{~mm}$. There was not any significant difference in measurement of upper lip by fetal sex. The length of palate in fetus was estimated to $16.7 \pm 1.8 \mathrm{~mm}$, and in the third trimester it was equal to $30.7 \pm 2.1 \mathrm{~mm}$. It compared by sex: in male it was estimated to $16.7 \pm 1.8 \mathrm{~mm}$, in female it was $16.6 \pm 1.8$ in the second trimester. However, the length was $30.5 \pm 2.0 \mathrm{~mm}$ in male, and in female it was estimated to $30.9 \pm 2.1 \mathrm{~mm}$. In comparison of second and third trimester of fetal palate in terms of the length, there was not any significant difference.

1) The height of fetal upper lip in the second trimester was estimated to $5.9 \pm$ $0.7 \mathrm{~mm}$ in female, and in male it was estimated to $6.0 \pm 0.6 \mathrm{~mm}$. For the third trimester: in female it was estimated to $9.5 \pm 0.9 \mathrm{~mm}$, in male it was $9.4 \pm 1.0$ $\mathrm{mm}$. There was no significant difference in fetal sex.

2) The length of palate in fetus was estimated to $16.7 \pm 1.8 \mathrm{~mm}$ in male, and in female it was $16.6 \pm 1.8 \mathrm{~mm}$ in the second trimester. In the third trimester in male it was estimated to $30.5 \pm 2.0 \mathrm{~mm}$, in female it was equal to $30.9 \pm 2.0 \mathrm{~mm}$. There was no significant difference in both sexes.

3) The lift and palate are developed gradually and in 20 week of gestational period it forms and gets its adult shape, in micro anatomy. Particularly, in 20-week of gestation, the muscular layer at the fusion of processes were thickened fused with other muscular layer and formed the bundle of muscle tissue.

\section{Conflicts of Interest}

The authors declare no conflicts of interest regarding the publication of this paper.

\section{References}

[1] Ayanga, G. (2012) Upgrade the Surgical Treatment for Congenital Palate. Stomatology Journal, UB.

[2] Vidar, M. (1997) Ultrasonographic Differential Diagnosis in Obstetrics. Yudina MBMEB, 1-10.

[3] Nyborg, W. (2002) Safety of Medical Diagnostic Ultrasound. Seminars in UItrasound, CT and MRI, 23, 377-386. https://doi.org/10.1016/S0887-2171(02)90008-9

[4] Horhler, C.B. (1994) Ultrasound Estimation of Gestational Age. Clinical Obstetrics and Gynecology, 27, 314-366. https://doi.org/10.1097/00003081-198406000-00007

[5] Axt-Fliedner, R., Schwarze, A., Kreiselmaier, P., Krapp, M., Smrcek, J. and Diedrich, K. (2006) Umbilical Cord Diameter at 11-14 Weeks of Gestation: Relationship to Nuchal Translucency, Ductus Venous Blood Flow and Chromosomal Defects. Fetal Diagnosis and Therapy, 21, 390-395. https://doi.org/10.1159/000092472

[6] Soegel, P., Pruggmayer, M., et al. (2006) Screening for Trisomy 21 with Maternal Age, Fetal Nuchal Translucency and Maternal Serum Biochemistry at 11-14 Weeks: A Regional Experience from Germany. Fetal Diagnosis and Therapy, 21, 264-268. https://doi.org/10.1159/000091353 
[7] Baterden, Ch. (2009) Health Indicators. National Department of Health Development, 9-19.

[8] Shijirbatar, B. and Battulga, G. (2012) Obstetrics and Gynecology. 7th Edition, Lippincott Williams \& Wilkins, Philadelphia, 24-25.

[9] Käferstein, F. and Abdussalam, M. (1999) Food Safety in the 21st Century. Bulletin of the World Health Organization, 77, 347-351.

[10] Shijrbatar, B. (2001) Obstetrics. Ulaanbaatar. 63 p.

[11] Avtandilov, G.G. (1990) Medical Morphometry. 382-410.

[12] Natsagdorg, B. and Munkhbat, G. (2004) Criminological Approaches and Histology. 32-33.

[13] Farkas, L.G., Hreczko, T. and Katic, M. (1994) Craniofacial Norms in North American Caucasians from Birth (One Year) to Young Adulthood. In: Anthropometry of the Head and Face, Vol. 2, Raven Press, New York, 241-312. 